Marquette University

e-Publications@Marquette

Psychology Faculty Research and Publications

Psychology, Department of

9-1-2019

\title{
Cusp Catastrophe Models for Cognitive Workload and Fatigue in Teams
}

Stephen J. Guastello

Marquette University, stephen.guastello@marquette.edu

Anthony N. Correro

Marquette University

David E. C. Marra

Marquette University

Accepted version. Applied Ergonomics, Vol. 79 (September 2019): 152-168. DOI. (C) 2018 Elsevier Ltd. Used with permission. 


\section{Marquette University}

\section{e-Publications@Marquette}

\section{Psychology Faculty Research and Publications/College of Arts and Sciences}

This paper is NOT THE PUBLISHED VERSION; but the author's final, peer-reviewed manuscript. The published version may be accessed by following the link in th citation below.

Applied Ergonomics, Vol. 79 (September 2019): 152-168. DOI. This article is (C) Elsevier and permission has been granted for this version to appear in e-Publications@Marquette. Elsevier does not grant permission for this article to be further copied/distributed or hosted elsewhere without the express permission from Elsevier.

\section{Cusp catastrophe models for cognitive workload and fatigue in teams}

Stephen J. Guastello

Marquette University, Milwaukee, WI, USA

Anthony N. Correro II

Marquette University, Milwaukee, WI, USA

David E. Marra

Marquette University, Milwaukee, WI, USA

\section{Abstract}

The use of two cusp catastrophe models has been effective for untangling the effects of cognitive workload, fatigue, and other complications on the performance of individuals. This study is the first to use the two models to separate workload and fatigue effects on team performance. In an experiment involving an emergency response simulation, 360 undergraduates were organized into 44 teams. Workload was varied by team size, number of opponents, and time pressure. The cusp models for workload and fatigue were more accurate for describing trends in team performance criteria compared to linear alternatives. Individual differences in elasticity-rigidity were less important than subjective workload and experimental conditions as control variables. Fluid intelligence within the team was an important compensatory ability in the fatigue model. Results 
further supported the nonlinear paradigm for the assessment of cognitive workload and fatigue and demonstrated its effectiveness for understanding team phenomena.

\section{Keywords}

Cognitive workload, Fatigue, Teams, Resilience, Cusp catastrophe, Emergency response

\section{Introduction}

A new phenomenon that has been garnering attention concerns the assessment of workload as it impacts the performance of groups (Funke et al., 2012; Helton et al., 2014; Sellers et al., 2014). Individual workload is defined as the demand placed on one's cognitive or physical energy and the work pace associated with it (Conrad, 1951; Hart and Staveland, 1988). A group's workload level comes from the same sources as individual workload, but there are added demands from group activity such as coordination, communication, and time sharing demands (Helton et al., 2014). High workload, or excessively low workload, produces fatigue, which is loss of work capacity over time (Starch and Ash, 1917; Kroll, 1981). Nevertheless, the effects of cognitive workload and fatigue have been difficult to separate analytically because they both depress performance simultaneously. Their effects are complicated further by momentum and practice effects, which can have a positive impact on performance (Ackerman, 2011; Guastello and McGee, 1987; Hancock and Desmond, 2001; Hancock and Warm, 1989; Matthews et al., 2012; Szalma and Teo, 2012).

Moreover, people may use coping strategies to reduce fatigue or manage workload, and these strategies exacerbate the difficulty of deconstructing the relationships between workload, fatigue, and performance, particularly if an attempt to curb fatigue results in a shift in workload management or vice-versa (Guastello et al., 2012a, 2013a, b; Hancock, 2007; Katidioti and Taatgen, 2014; Rubinstein et al., 2001; Wickens, 2002, 2008). Although coping strategies are often intended to maintain the stability of performance under conditions of changing workload demands (Hancock and Warm, 1989), some strategies, or the psychosocial variables related to them (e.g. Gruszka et al., 2010; Hockey, 1997, 2011, 2012; Szalma, 2012), can have both positive and negative effects of performance (Guastello, 2014; Guastello et al., 2015b, 2017a).

A solution to the nexus of problems associated with individual responses regarding workload, fatigue, coping, or resilience has involved the use of distinct catastrophe models for (a) the workload response and (b) the fatigue response. Both models must be examined separately but simultaneously in the same work context in order to effectively parse the impact of both workload and fatigue on performance. Thus far, the models have captured performance dynamics effectively with individuals and teams of two co-workers. Both models predict discontinuous changes in performance (Guastello, 2014a, 2016a; Guastello et al.,

2012a,, b, 2013a, 2014, 2015a, 2016).

The objectives for the present study were to examine the two cusp models for cognitive workload and fatigue again with teams of different sizes and to examine further how individual experiences contribute to group-level responses. The following sections of this article explain the models, the contributing variables, the role of subjective ratings, and the experimental context that involved an emergency response (ER) simulation.

The performance criteria for this simulation were defined for the team rather than for individuals. As such, an additional aspect of analysis involved aggregating individual scores on elasticity-rigidity variables and individual ratings of workload into group-level measurements.

\section{Cusp catastrophe models for cognitive workload and fatigue}

Catastrophe theory (Thom, 1975; Zeeman, 1977) has been widely useful for describing and predicting discontinuous events. Its central feature is a set of seven topological models, which vary in the number of stable states, unstable states, and control parameters that they contain. The cusp model (Fig. 1 ) is the second simplest and the most often adopted model in psychological applications. It features two stable states of behavior 


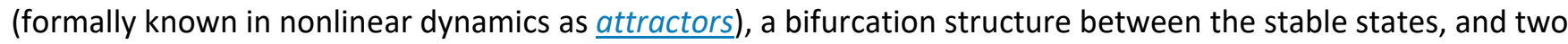
control parameters. The control parameters, asymmetry $(a)$ and bifurcation $(b)$ govern the degree of change in system performance and the proximity of the system to critical points where change occurs. At low values of $b$, change is smooth, that is, $y$ is a continuous and monotonic function of $a$.

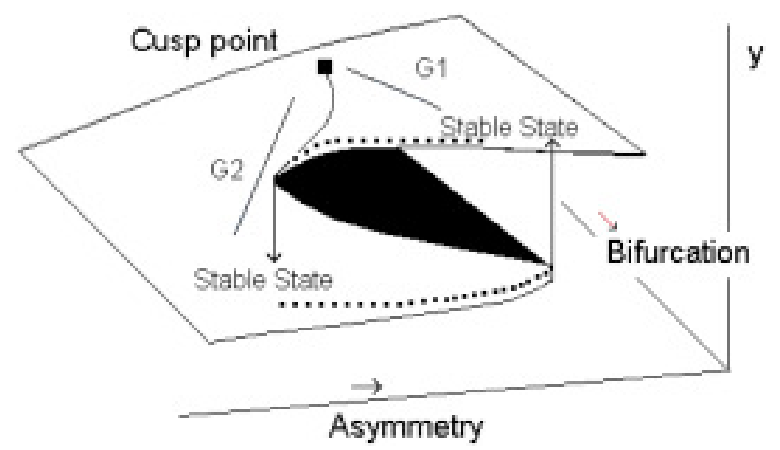

Fig. 1. Cusp catastrophe model.

To visualize the dynamics, start at the stable state on the left (see Fig. 1) and follow the outer rim of the surface where bifurcation is high. If the value of the asymmetry parameter shifts, nothing happens until it reaches a critical point, whereupon a sudden change in behavior is observed. Specifically, the control point, which indicates what behavior is operating, flips to the upper sheet of the surface. This is where the discontinuous change in system behavior occurs. A mirror imageprocess occurs when shifting from the upper to the lower stable state. Notice that the upward and downward paths occur around different thresholds.

When the bifurcation effect is low, change in system behavior is relatively smooth. The darkened area between the stable states (attractors) is an area where few data points are likely to land because a repellor is located there. A repellor is a negative form of attractor; points or objects that get too close to it are pushed away. The cusp point, generically known as a saddle, is the most unstable location on the surface. Points or objects are drawn to it but are rapidly redirected elsewhere (e.g. to available attractors).

The paths drawn between the cusp point and the stable states (in Fig. 1) are gradients. Research variables, which are often drawn from diverse behavioral measurements, do not necessarily reflect sterling examples of asymmetry and bifurcation parameters. In fact, they might have properties of both parameters (Guastello, 1995, 2013b; Guastello and Gregson, 2011). Thus, when a cluster of such variables is used together, it is possible that some variables could be slanted toward the upper attractor on a response surface and other variables could be slanted toward the lower attractor on the surface. In those cases, the variables would take on the character of gradients.

When a control point starts to make the transition across the response surface from one stable state to the other, there is often a substantial burst of variability in behavior. The variability is often accompanied by "stickiness" as the point moves at an irregular pace as it breaks free of one attractor to find the other. In doing so it is often pulled back to the previous attractor before it has fully reached the basin surrounding the new attractor. These temporal patterns are collectively known as hysteresis, and signify a high probability of a catastrophe function when they are observed (Gilmore, 1981).

The deterministic equation for the cusp catastrophe response surface is:

$$
\delta f(\mathrm{y}) / \delta \mathrm{y}=\mathrm{y} 3-\mathrm{by}-\mathrm{a}
$$


in which $y$ is the dependent measure that displays the discontinuities, and $a$ and $b$ are the control parameters. Importantly, catastrophe models can be tested using a statistical analysis that is specific to the model (Guastello, 1995, 2013a; Guastello and Gregson, 2011). The statistical tests of the model can be performed using a dynamic difference equation with polynomial regression or a static model that is based on the statistical distribution of the cusp calculated through nonlinear regression. Both types of analysis were used in this study.

Catastrophe models are part of a broader inventory of nonlinear dynamical processes that have been useful for studying changes in system behaviors over time. Other types of temporal dynamics include chaos, fractals, and several other types of attractors, bifurcations, and self-organizing processes (Guastello and Liebovitch, 2009; Sprott, 2003). Nonlinear dynamics have become the basis of a scientific paradigm that extends across many domains in the physical and social sciences. The paradigm is particularly useful in ergonomics in light of its growing concern for the behavior of complex sociotechnical systems, which can exhibit all sorts of dynamical patterns (Guastello, 2017; Karwowski, 2012).

One category of problems with complex systems that currently intrigues the research community is how grouplevel cognitive processes emerge from the interactions among individuals. These phenomena are essentially examples of collective intelligence (Guastello, 2013b; Sulis, 2009). Some (but not all) emergent processes involve phase shifts - sudden discontinuities in the system's structure or function. Phase shifts, when sufficiently understood and analyzed are catastrophe processes, and they are one of a few manifestations of self-organizing processes (Goldstein, 2011; Guastello, 2005).

Another category of problems with complex systems concerns the design of large-scale systems composed of many person-machine modules (Boehm-Davis et al., 2015; Hollnagel, 2012). Although the majority of these potential applications have not yet developed to the stage where nonlinear dynamical systems analysis has been applied directly, one only has to remember the theorem (Newhouse et al., 1978) that three coupled oscillators are sufficient to produce chaos. Systems in a state of chaos or other high entropy condition tend to self-organize to conserve potentially wasted energy. If they do not exhibit a phase shift, they often acquire a fractal structure, which triggers another interesting question: How do the structure and dynamics of lower level system components compare with, if not fully mimic, structure and dynamics at more macroscopic levels? The question of levels is inherent in the present investigation since the central question is how does the pair of models that aptly describe cognitive workload and fatigue at the individual level transport to (or scale to) a group process.

Regarding the catastrophe models generally, the applications that have been published since Thom (1975) and Zeeman (1977) are vast. For applications of the cusp model specific to human factors and ergonomics, however, see Guastello (2014b, 2017). Recent applications of the cusp to a broader range of organizational behavior and groupdynamics include job performance (Alessandri et al., 2018; Naber et al., 2015; Rebelo et al., 2016), decision strategies (Butner et al., 2014; Oliva and McDade, 2008; Stamovlasis and Vaiopoulou, 2017; Katerelos and Varotsis, 2017); bullying (Escartin et al., 2013), development and diffusion of innovation (Hazy and Boyatsis, 2015; Jacobsen and Guastello, 2007, 2011; Katerndahl, 2011), and motivation problems (Stamovlasis and Sideridis, 2014). For older applications concerning various problems in work performance and organizational behavior, see Guastello (1995, 2002, 2013a).

\subsection{Workload model}

Cognitive workload is the amount of information that a person can process in a limited time frame. Although it is convenient to imagine workload capacity in terms of bits per second, the number of bits anyone can process is highly dependent on the task (Kantowitz, 1985). Experimental evidence at one point in time supported both the notions of fixed and variable upper limits to human channel capacity. A more recent understanding now supports the variable upper limit explanation. There are some important degrees of flexibility associated with auditory, visual, and other modes of processing within working memory (Baddeley, 2003), alignments of stages 
of processing for two or more simultaneous tasks (Wickens, 2002, 2008), and the recruitment of neural circuitry by the executive function of working memory (Reuter-Lorenz and Cappell, 2008).

The workload model (Fig. 2) is analogous to Euler buckling of an elastic beam (Guastello, 1985, 2003). The mathematical association between Euler buckling and the cusp model is literal as opposed to metaphorical (Zeeman, 1977). The asymmetry parameter, which governs the proximity of the system to the thresholds for sudden change, is the workload that is placed on the system or, in this case, the human operators. The bifurcation parameter, which governs the degree of discontinuity, is elasticity versus rigidity of materials such as metals, plastics, living tissues, and composites.

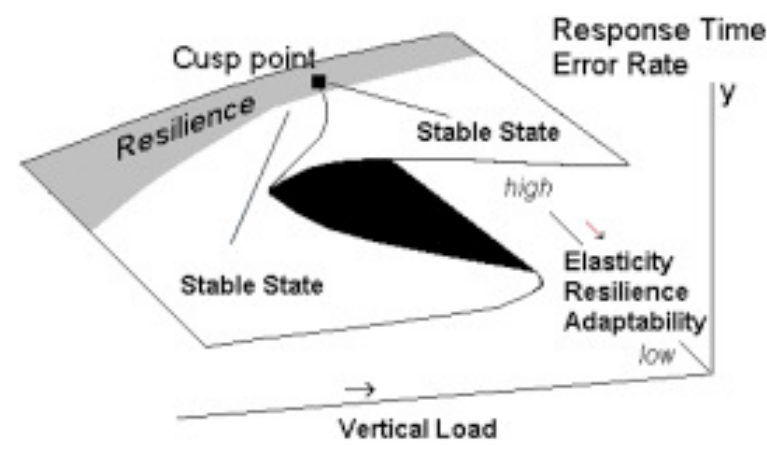

Fig. 2. Cusp catastrophe model for workload.

$\underline{\text { Individual differences in cognitive abilities, }}$ personality, or other psychosocial variables make up a substantial portion of the elasticity-rigidity parameter in the workload model. For instance, a person who is rigid in the sense of the trait conscientiousness would likely stick to standard procedures and task scheduling, even when faced with anomalous situations requiring special attention in some way. A more flexible individual would consider rearranging a batch of tasks to allow those that arrived later to move forward sooner if they did not require special handling. A flexible individual might imagine different methods of doing the task that work around the problematic elements. The rigid approach would maintain performance quality and quantity without introducing new forms of decision complexity, which could induce more mental workload, but the rigid approach only works up to a point until the anomalies pile up and produce a bottleneck. The more flexible approach finds the best procedure for the moment while maintaining the objective of maximizing throughput quickly.

Hysteresis has been reported in other workload research, although without a specific reference to the cusp catastrophe model or its specific forms of analysis (Hancock et al., 1995; Jansen et al., 2016; Morgan and Hancock, 2011). The gist of the phenomenon runs as follows: Performance drops as a result of adding stress (workload in this case), but remains depressed when the stress is removed. This effect has been variously interpreted as persistent coping or a type of resource depletion (Cohen, 1980). This persistence of low performance is an example of the stickiness associated with the high-error/low-performance attractor in the cusp model. Hysteresis in workload dynamics suggests persistent coping explanation is more consistent with the workload dynamics, while hysteresis in fatigue dynamics reflects resource depletion.

As an illustrative example of hysteresis in a workload experiment, Jansen et al. (2016) prepared a driving task with a secondary task of responding to police calls on the radio. They had a sequence of low, high, and low workload conditions and reported hysteresis in the form of performance volatility on a memory task and driving speed in the high workload condition. Hysteresis persisted in the second low workload condition; the task that was more affected depended somewhat on whether the drivers were given an instruction to treat both tasks equally or to give priority to driving. This zig-zagging pattern of performance is an example of movement around the bifurcation manifold. There would be less stickiness if the attractor points were not reached during the fluctuations or if the time frame associated with each measurement were long enough to envelop all the 
stickiness that could exist. It is noteworthy that hysteresis has also been evident in workload research that was designed through a more conventional paradigm.

\subsubsection{Elasticity-rigidity}

Previously, several elasticity-rigidity measurements have acted as bifurcation variables across different types of tasks when using the cusp model for workload. The construct of elasticity as used here bears a close

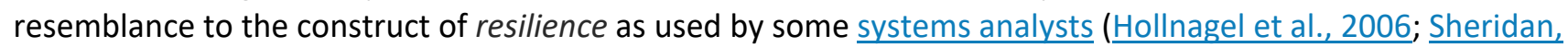
2008) and clinical psychologists (Pincus and Metten, 2010). It also bears some resemblance to the construct of antifragility (Kiefer and Myer, 2015; Taleb, 2012). Whereas "resilience" is often used to describe a person or system's ability to recover quickly from a (highly) stressful situation, "antifragility" describes a person or system that is not seriously affected by situations that would be calamitous for others. An antifragile system is capable of adapting by making good use of the available degrees of freedom in a situation; this is an example of the optimum variability principle (Guastello, 2017; Schuldberg, 2015). An antifragile system could be trained or developed with exposure to perturbations (Gorman et al., 2017; Kiefer and Myer, 2015; Shockley et al., 2009).

It is noteworthy that a high-resilience state is potentially unstable in the workload model because it is located at the cusp point, which is the most unstable point on the cusp response surface (see Fig. 1). Once a resilient effort has occurred successfully, the system needs to lock it into place by essentially adjusting either or both control parameters to steer the system toward a stable attractor. That can be done by protecting workload against extreme surges (asymmetry) or by making the resilient response more of a habit than a temporary innovation (bifurcation moving toward rigidity).

Known individual differences in elasticity-rigidity fall into four categories - affect, coping, fluid intelligence, and conscientiousness. These represent a mixture of psychosocial and cognitive elements. They were all identified in previous studies with the cusp model for workload. However, they were not all relevant to the model each time they were investigated with a different task. A fifth source of elasticity-rigidity is sometimes found in the task itself, such as whether the individual can switch among multiple tasks at will or must stay confined to a specific regimen (Guastello et al., 2013b). The ER task in the present study did not contain this source of flexibility.

A question investigated in this study was whether the individual differences in elasticity-rigidity observed at the individual level have the same effect at the group level of analysis. Naber et al. (2015) showed that if groups of four participants contained at least one person who scored high on a measure of trait anxiety, anxiety produced a bifurcation effect on team performance. The strategy for the present study was to count the percentage of participants in a team scoring high on the elasticity-rigidity variables.

\subsubsection{Affect constructs}

Not only can trait anxiety slow response time, interfere with lucid decision making (Cox-Fuenzalida et al., 2006), and increase frustration with a task (Rose et al., 2002), but it can also have a positive impact on performance by narrowing attentional resources to details that other people might miss (Ein-Dor et al., 2010). Its bidirectional influence supports its candidacy as a bifurcation variable in a cusp catastrophe model. A person's level of trait anxiety is more likely to become relevant to performance when interpersonal challenges or physical hazards are present (Guastello et al., 2012b; Guastello and Lynn, 2014; Naber et al., 2015) or when workload is too low (Vyal et al., 2012). In the latter case, too much mental workspace is being occupied by task-unrelated ruminations. Experimentally induced state anxiety or negative affect also has a history of inducing rigidity (Liu and Wang, 2014), whereas positive affect promotes flexibility. Flexibility can be complicated by distractibility, however, depending on whether the experimental task is goal-oriented or not.

Emotional intelligence (EI) facilitates the understanding of one's own emotions and the emotional messages from other people. This understanding can aid the individual in forming appropriate actions in response to emotions. Low El denotes rigidity in the form of indifference, which could be a buffer against stress effects. 
When stress gets too high, however, the system can buckle and snap producing any of a number of abreactions if the individual is not aware of his or her own emotional level or those of other people (Thompson, 2010). et al. (2010) likened the abreactions within a complex cognitive-emotional system to that of squeezing a balloon-squeeze it in one place, and the balloon stretches; squeeze it further, and it pops.

Empathy bears some conceptual overlap with El, and thus it would also act as a bifurcation variable. Empathy is usually defined with both a cognitive and an emotional component. The cognitive component is the ability of one person to take the point of view of another. The emotional component is the ability to vicariously experience the emotions of other people. Empathy might also contain other facets such as self-regulationof emotion (Gerdes et al., 2011; Lietz et al., 2011), particularly when responding to co-workers (Guastello, 2016b).

Frustration also falls within the affect-related cluster of bifurcation constructs. A frustrated individual could channel the reaction positively to maintain or improve performance. A frustrated individual could also abreact and either withdraw from the task entirely or, in laboratory studies, withdraw psychologically from trying to solve the task-relatedproblems. Previous studies of the cusp model for workload (Guastello et al., 2014, 2015a) measured task frustration with the NASA Task Load Index (TLX; Hart and Staveland, 1988).

\subsubsection{Coping constructs}

One construct of coping flexibility is centered on emotional adjustments in the clinical sense of long-term life issues (Kato, 2012). People who have a broader repertoire of coping strategies are likely to be more resilient to stress and emotional hardship. Another construct is oriented toward cognitive strategies such as planning, monitoring, decisiveness, and inflexible responses to changing work situations (Cantwell and Moore, 1996). All strategies would denote rigidity and, like anxiety, could reflect the potential for an adaptive or maladaptive response. Coping has played important roles as bifurcation variables (elasticity-rigidity) in the workload models for a vigilance task (Guastello et al., 2016) and an N-back task (Guastello et al., 2015a), which also placed a heavy demand on working memory.

\subsubsection{Fluid intelligence constructs}

Working memory, which is a limiting ingredient in workload tolerance, is part of the broader mental operations of fluid intelligence (Kane and Engle, 2002; Kane et al., 2005). Field independence is a cognitive style that separates perceptions of a figure from a background. People with high field independence are likely to use more of their working memory capacity in a challenging task (Pascual-Leone, 1970). Stamovlasis (2006, 2011; Stamovlasis and Tsaparlis, 2012) found that field independence functioned as a bifurcation variable in studies of mental workload in chemistry problem solving, suggesting its analytical importance to performance and workload models. In a later study using a financial decision-making task, field dependence was associated with the high-bifurcation side of the cusp response surface, and it was also correlated with greater risk-taking overall (Guastello, 2016a).

One's ability to solve anagrams reflects one of several cognitive measures of creativity (Barron, 1955) and fluid intelligence (Hakstian and Cattell, 1978). Previously, performance on an anagram test played a small but consistent role in predicting smaller changes in risk-taking under conditions of fatigue, but not workload, in a financial decision making task, which was an optimizing task rather than a creative problem solving task (Guastello, 2016a). It was thought possible that tolerance for ambiguity, which is associated with creative thinking, could explain performance advantages, but additional research is required. Ability to solve anagrams was examined again in the present study as a possible elasticity-rigidity variable.

Algebra flexibility is based on the idea that, in addition to learning the rules of algebra, students should be flexible in their use of algebraic principles to solve problems (Rittle-Johnson and Star, 2009; Rittle-Johnson et al., 2009; Schneider et al., 2011). The construct takes the form of a test with word problems that require the respondent to compare methods for getting the problem started or organizing the procedure for solving the 
problem. Algebra flexibility played a salient role as a bifurcation variable in the cusp model for workload using an $\mathrm{N}$-back task (Guastello et al., 2015a); greater flexibility with algebra was associated with less rigidity under increasing workload and better performance overall.

\subsubsection{Conscientiousness constructs}

Conscientiousness in the five factor model of personality traits (Costa and McCrae, 1992) is a trait that predisposes one to pay close attention to details, rules, and task orientations. The trait also includes planfulness and a lack of impulsivity. It thus implies a type of rigidity (MacLean and Arnell, 2012). In some earlier workload experiments, conscientiousness was measured as a broad trait. In others, it was analyzed as two narrower traits. One measured conscientiousness in the sense of Factor $\mathrm{G}$ on the Sixteen Personality Factors Questionnaire

(16PF; Cattell, 1994; Guastello et al., 2015b), which extends to the predisposition to attend to details and so forth, while the other measured impulsivity versus self-control, which would be similar to Factor Q3 on the 16PF. In principle, it is possible for people to be rigid in the sense of Factor $G$ and flexible in the sense of Q3 (Guastello, 2016a). Previously, impulsivity was correlated with higher ratings of TLX temporal demand, and the narrower form of conscientiousness was correlated with higher ratings of TLX performance. The conscientiousness variables were not included in the present study because they were thought to be least relevant to the task, and it was necessary to contain the number of measurements required of the participants.

\subsection{Fatigue model}

Fatigue has been traditionally defined as a loss of work capacity over time that comes from prolonged time on a task (Mosso, 1894). The idea was illustrated repeatedly as a performance curve showing initial stability in performance followed by a sharp decline. The same definition carried over to cognitive fatigue (Ackerman, 2011; Ash, 2014; Dodge, 1917; Starch and Ash, 1917). Other performance curves are possible such as sustained high or low performance or rebound effects after a rest period or switching tasks. It was later shown that the system of possible curves can be adequately represented by a cusp catastrophe model (Guastello and McGee, 1987).

In the fatigue model (Fig. 3), the bifurcation parameter is the amount of work done between two measurement points in time, and the asymmetry parameter consists of compensatory abilities or learning conditions. Individual differences in cognitive abilities contribute to the compensatory ability parameter in the fatigue model. The model is again bidirectional. Performance can go up or down over time. Fatigue is typically understood as a unidirectional loss of work capacity over time, yet work that fatigues some individuals might enable others to get "warmed up." Practice and momentum effects would be part of that warm-up process.

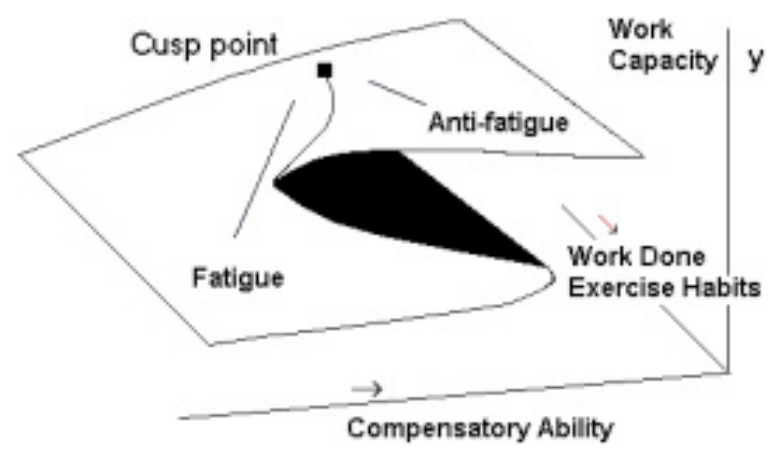

Fig. 3. Cusp catastrophe model for fatigue.

Another feature of fatigue that carries over to the cusp model is that there is a substantial increase in the variability of performance that accompanies the net decline in performance over time. The variability would occur around the curved manifold in the middle of the cusp surface between the cusp point and the area where 
the bifurcation effect is the widest (Guastello, 2016a; Guastello and McGee, 1987). Fatigue in that context and in the context of the present study reflects the effects of time on task performance and does not assume any additional complications from sleep loss or disturbances. Performance dynamics associated with sleep issues can be studied as cusp functions also, however (Guastello, 2003).

The resource depletion associated with physical tasks can be associated with overworking particular muscle groups. A certain amount of it, however, can be attributed to overworking the neural circuits that move the muscle groups (Hong, 2010); the latter point is also an important explanation for cognitive fatigue. The variability in performance associated with fatigue signals a search by the system for alternative neural circuits that can do the same job. Alternative outcomes for the individual would be to quit the task altogether, take a rest, or perhaps switch to a different task.

\subsubsection{Compensatory abilities}

The earliest efforts to study cognitive fatigue through the catastrophe paradigm stuck close to the physical labor prototype (Guastello and McGee, 1987). In that case, fatigue was evidenced by a drop in a primary capacity, such as arm strength, and the compensatory ability was a related capacity, such as leg strength. Later efforts took advantage of the developments in cognitive research. Historically cognitive fatigue is incurred by the

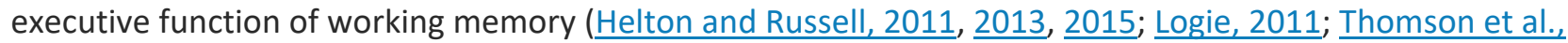
2015). The executive function of working memory allocates mental workspace for multiple cognitive domains to operate or for several pieces of information to be processed at the same time (Oberauer and Kleigel, 2006). Fig. $\underline{4}$ summarizes the connection between cognitive workload, fatigue, and the primary facilities of working memory. The separation between the functions of working memory and their effects on performance is not quite as clean as it may appear in Fig. 4. Mental workspace is also allocated to the executive functions themselves, and the resources for executive and more basic functions appear to be drawn from a common pool or resources (Barrouillet et al., 2011). As a result, demands placed on executive functioning impact workload in the shorter term and fatigue with longer time on task.

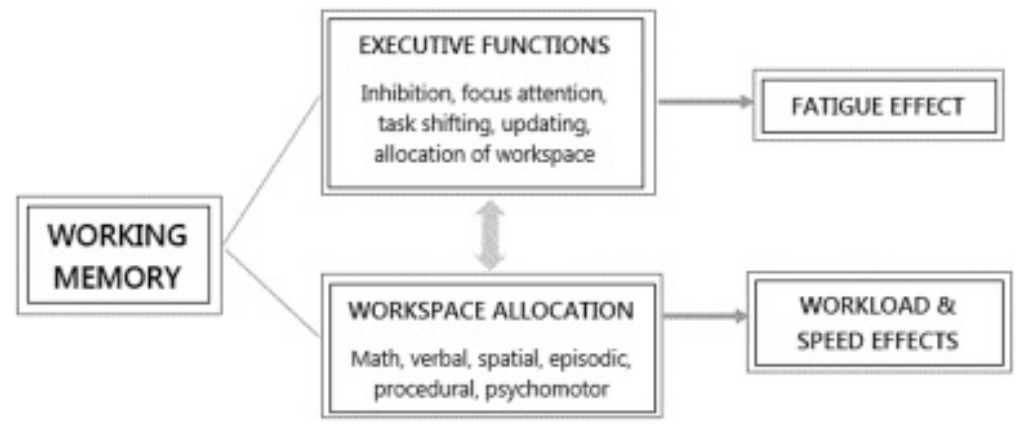

Fig. 4. Cognitive workload, fatigue and working memory functions. Reprinted from Guastello et al. (2016, p. 516) with permission from the Society for Chaos Theory in Psychology \& Life Sciences.

Compensatory abilities cognitive fatigue studies using the cusp model have included speeded arithmetic in an episodic memory task (Guastello et al., 2012c), episodic memory performance in a picture-matching task (Guastello et al., 2012a), speeded spelling corrections with a perceptual-motor multitask (Guastello et al., 2013a), field independence and anagrams in a financial decision making task (Guastello, 2016a), and algebra flexibility in an N-back task (Guastello et al., 2015a). Note that the fluid intelligence constructs that worked as elasticity-rigidity variables in the workload model sometimes played a role as compensatory abilities in the fatigue model. Some of the previous studies had experimental conditions that contributed to performance as compensatory abilities (asymmetry) because they (presumably) represented styles of training that could make the task easier or more difficult, such as presenting stimuli in decreasing speed over time versus presenting them in increasing speed over time (Guastello et al., 2014). 


\subsubsection{Relationship to workload}

Researchers continue to grapple with the relationship between workload and fatigue and whether they constitute one process or two separate processes. Fan and Smith (2017) presented a study in which subjective ratings of workload and fatigue both affected changes in performance on a set of cognitive tests. Subjective workload and fatigue were correlated such that when they were combined subjective fatigue predicted performance differences, but subjective workload did not add any further prediction.

The rationale for using the two cusp models in the present study is that workload and fatigue involve two different performance dynamics. In many situations the two processes could be operating over different time horizons, such that workload effects would be apparent over relatively shorter time horizons as workload levels changed, whereas fatigue would be observed over a longer period of time. Each model accounts for performance differences, such that workload effects are observed across workload conditions, and fatigue results from prolonged time on task. Fatigue (and antifatigue) in the cusp model is greater to the extent that the individual (or group) accomplishes more work during the time period between measurements. If the participants are performing tasksunder different levels of workload, the high workload condition makes an additional contribution to the amount of work done, and should be represented as a bifurcation variable.

\section{The present study}

The present study involved an emergency response (ER) simulation in which teams of three, four, seven, or eight participants worked against one or two opponents (attackers). Time limits for each turn were also manipulated. Because the performance measures were generated at the group level only, elasticity-rigidity variables were measured at the individual level then aggregated into group measurements. Similarly, the subjective ratings of individual and group workload needed to be aggregated into group-level measurements. Some theoretical issues associated with these manipulations are outlined next.

\subsection{Group size}

Group dynamics result from self-organizing dynamics in which the interactions among group members affect the development of the global dynamics, which in turn shape the behavior of individuals within the system (Sawyer, 2005). Smaller groups, usually in the scale of three to six members, are more likely to be psychologically homogenous, cohesive, and successful in many types of task performance (Whelan, 2009; Zander, 1994). People in smaller groups tend to take relatively equal numbers of turns in a conversation. As groups become larger, however, more speech turns are taken by proportionately fewer people (Bonito and Hollingshead, 1997). This trend could be problematic for tasks that require some creative problem solving and the need to engage the critical mass of ideas.

Larger groups in the range of 8-12 members are more likely to be psychologically heterogeneous and thus more likely to produce the critical mass of ideas that are required for both creative problem solving tasks and for making the group more productive than the most competent individual (Dennis and Valacich, 1993). Nevertheless, larger groups are more prone to conflict for the same reasons (Zander, 1994) and tend to evolve more slowly in their internal dynamics as they make the transition from over-reliance on the leader to acting autonomously (Whelan, 2009).

Social loafing is a phenomenon in which some group members do more of the work than others while they all share in the same reward (Latané et al., 1979). If or when loafing occurs, it could potentially alter workload demand on some group members. Social loafing could occur in groups of any size, but it is more so frequent in 
larger groups because it can be more difficult for individuals to see the meaningfulness of their contributions to the group objectives (Comer, 1995). Differential work production or participation input, however, is not always a result of deliberate loafing; it can also result from poor team coordination (Guastello, 2009).

Hypotheses regarding group size can have four generic outcomes (Guastello, 2010): (a) If the relationship between size and performance favors larger groups, the relationship is probably driven by the need for a critical mass of ideas or other input. (b) If the relationship favors smaller groups, the relationship is probably driven by coordination and conflict issues. (c) If the relationship is curvilinear, then a trade-off between the advantages of smaller and larger group sizes is evident. (d) If there is no relationship to group size, then it is likely that the team's task is being performed by the most competent members of the group, that there is a widespread lack of understanding of the task, that there is widespread social loafing, or that some combination of these conditions is occurring.

\subsection{Workload and speed}

Workload was manipulated by the number of opponents competing against the team. The ER simulation used in this study involved either one or two attackers that the ER teams needed to eliminate. The two-attacker scenario should add workload for the ER teams because it creates a more challenging problem for the ER groups to overcome. The two-attacker scenario should also add to the amount of work accomplished in the fatigue model because of the added complications associated with eliminating either of the two attackers when the two act simultaneously.

Time pressure is another form of workload that was manipulated in the experiment. In an early ergonomics study, Conrad (1951) showed that when speed and sources of demand (workload) were multiplied together they had a strong linear correlation with individuals' task performance. Speed and load manipulations have also been studied as separate measures (Cox-Fuenzalida et al., 2006; Guastello, 2016a; Guastello et al., 2012b, 2014, 2015a; Kantowitz and Sorkin, 1983; Szalma and Teo, 2012). Speed stress typically does not have a visible impact on performance errors until it reaches a critical point when a speedaccuracy trade-off is observed (Kantowitz and Sorkin, 1983).

\subsection{Subjective workload}

Differences in workload that arise from various task conditions are not always apparent in task performance because individuals can employ coping strategies that buffer high and low workload levels (Hancock and Warm, 1989; Ralph et al., 2010). As a result, subjective ratings of workload, such as the NASA Task Load Index (TLX; Hart and Staveland, 1988) have become valuable tools for research and the evaluation of system designs (Guastello et al., 2015b; Hart, 2008). The TLX measures mental demands, physical demands, temporal demands, performance demands, effort required, and frustration (see Table 1).

Table 1. Individual and group work scales. Individual Scales, NASA TLX

MENTAL DEMAND: How mentally challenging (ex. thinking, searching, deciding) was the task? PHYSICAL DEMAND: How physically challenging (ex. pushing, pulling) was the task?

TEMPORAL DEMAND: How much pressure did you feel performing the task because of the pace of the task?

\section{Group Workload Scales}

COORDINATION DEMAND: How much coordination activity was required (e.g., correction, adjustment)? Were the coordination demands to work as a team low or high, infrequent or frequent?

COMMUNICATION DEMAND: How much communication activity was required (e.g. discussing, negotiating, sending and receiving messages)? Were the communication demands low or high, infrequent of frequent, simple or complex?

TIME SHARING DEMAND: How difficult was it to share and manage time between taskwork (work done individually) and teamwork (work done as a 
team)? Was it easy or hard to manage individual tasks and those tasks requiring work with other team members?

PERFORMANCE: How successful were you at achieving the goals of the task?

EFFORT: How much energy was put forth to achieve your level of performance on the task?
TEAM EFFECTIVENESS: How successful do you think the team was in working as a team? How satisfied were you with the team-related aspects of performance?

TEAM SUPPORT: How difficult was it to provide and receive support (providing guidance, helping team members, providing instructions, etc) from team members? Was it easy or hard to support/guide and receive support/guidance from other team members?

TEAM DISSATISFACTION: How emotionally draining and irritating vs. emotionally rewarding and satisfying was it to work as a team?

FRUSTRATION: How discouraged bothered, irritated, and annoyed were you because of the task?

a) Reprinted from NASA Hart and Staveland (1988). In the public domain.

b) Reprinted from Helton et al. (2014). In the public domain.

The widespread nature of teamwork in sociotechnical systems has generated some new questions about group

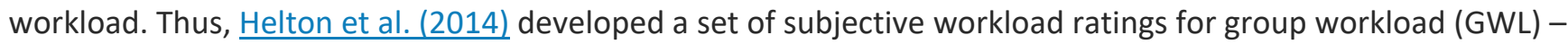
coordination demand, communication demand, time sharing demand, team efficacy, team support, and team dissatisfaction - which were meant to parallel the TLX rating constructs. Instead of using TLX and GWL ratings as criterion measures, which has been the case for most prior uses of those ratings, the present study is incorporating them into the cusp models as additional asymmetry and bifurcation variables. By doing so it would be possible to capture some of the psychological processes that might impact the response to the experimental workload conditions, the individuals' elasticity or rigidity, and the performance outcomes.

The use of TLX and GWL ratings engendered two methodology issues concerning the aggregation of scores. The first concerns transforming the individuals' ratings of workload to a group-level measurement. It appears that adding or averaging the individual ratings together to make a group score produces adequate measures of group workload (Funke et al., 2012; Helton et al., 2014). The second issue was whether the six TLX and the six GWL ratings can be added together to make single total scores and how to represent them in the cusp model for workload. The TLX has been used as a single total score numerous times although some researchers prefer to examine the six ratings separately. When they have been included in cognitive workload studies with the cusp model, they have been treated as separate measures (Guastello et al., 2012a, 2015a, 2016). Mental demand, physical demand, and temporal demand represent features of the specific task conditions that induce workload and would thus correspond to sources of workload as defined by the asymmetry parameter in the cusp model. They sometimes do not contribute anything to the cusp model beyond what would be accounted for by the sources of workload in the experiment (Guastello et al., 2014, 2015a, 2016). Performance, effort, and frustration reflect individual differences and have shown statistically unique effects as bifurcation variables. For the present study, mental, physical and temporal demand were added together to form an asymmetry variable while performance, effort and frustration were added together to form a bifurcation group.

Sellers et al. (2014) showed that the TLX and GWL ratings can be separated (factored) into two components, which supports the distinctiveness of the two sources of workload. Others have recently reported, however, that scales representing the two types of workload combine differently when sources of workload are varied within an experiment (Guastello et al., 2017a; Guastello and Marra, 2018). GWL ratings have also shown correlations with individual differences in elasticity-rigidity (Guastello et al., 2017b). Because the latter results were complicated and the generalizability of their use is not yet known, GWL ratings were treated as a single bifurcation variable in the workload model. 


\subsection{Hypotheses}

The hypotheses for this study fall into three categories: aggregation of elasticity-rigidity variables, cusp models for workload, and cusp models for fatigue.

1. A components analysis of elasticity-rigidity variables should reveal some emergent themes among the variables that could either reflect the categories of elasticity-rigidity variables previously described or reflect other patterns that have not yet been identified. In either case, a components analysis should simplify the range of constructs. The simplification of constructs would have both theoretical value and practical value when conducting regression-based analyses.

2. The cusp model for workload should be a more accurate description of group-level performance trends than linear alternatives.

a. Experimental conditions for group size, time constraints, and number of opponents should contribute to the asymmetry parameter because they are sources of workload. These potential sources of workload had an impact on subjective workload in a previous study that used the same data as the present study (Guastello and Marra, 2018). The hypothesized model that involved time constraints was tested in two novel ways: one involved comparisons of performance within one experimental session, and the other examined changes in performance across two experimental sessions.

b. Group size should also contribute to the asymmetry parameter. The results could favor either smaller groups because they would induce less coordination demand or larger groups because they produce a critical mass of ideas in a task that is primarily cognitive.

c. TLX ratings for mental, physical, and temporal demands should contribute to the asymmetry parameter.

d. Elasticity-rigidity variables should contribute to the bifurcation parameter. An alternative result is that elasticity-rigidity would be subsumed in the TLX or GWL ratings because, in a previous study, both types of ratings were affected by individual differences in elasticity-rigidity (Guastello et al., 2017b).

e. TLX ratings for performance, effort, and frustration should contribute to the bifurcation parameter because they reflect human responses to actual differences in workload, similar to the role played by elasticity-rigidity variables (see Guastello et al., 2014, 2015a).

f. GWL ratings of workload should contribute to the bifurcation variable because they reflect human responses to differences in situations in a similar fashion as TLX ratings of performance, effort, and frustration.

3. The cusp model for fatigue should be a more accurate model for group level performance trends than the linear alternative.

a. Fluid intelligence variables should contribute to the asymmetry parameter as compensatory abilities.

b. Experimental conditions for time constraints and number of opponents should contribute to the bifurcation parameter because they reflect more work accomplished in the same amount of time.

c. Group size should contribute to the bifurcation parameter because it reflects more work related to group processes or having more people producing a critical mass of ideas.

d. The second of two data collection sessions would have a positive effect on performance changes within the session as captured by the fatigue model. A team that was more experienced in working together would find the task less demanding; this hypothesis follows from the antifatigue aspect of the model in which momentum and learning can counteract the negative impact of time on task. 


\section{Methods}

\subsection{Participants}

This study was approved by the university's Institutional Review Boardwith regard to all matters pertaining to the use of human research participants. Participants were 360 undergraduates who were enrolled as students in psychology courses in a Midwestern USA university. Their ages ranged from 18 to $31(M=19.04, S D=1.32)$. There were 102 males, 255 females, and 3 people who did not report gender. They were organized into 44 groups and participated in three experimental sessions. Participants were generally unfamiliar with the other members of their group prior to meeting during the experiment. The recruitmentgoal was to assemble four or eight participants for the ER teams, one or two to play the attackers, plus one more as an alternate in case one player did not show up for an experimental session. Attrition usually occurred after the first session. Sessions were scheduled one week apart. There were 252 ER team members, 65 attackers, and 43 observers, respectively, who completed the simulations for data collection purposes. The breakdown of participants in the small and large group conditions with one or two attackers appears in Table 2.

Table 2. ER team sizes by experimental condition.

\begin{tabular}{|l|l|l|l|l|}
\hline Attackers & \multicolumn{2}{|c|}{ Small } & & \multicolumn{2}{c|}{ Large } & \\
\hline & No. Groups & Size & No. Groups & Size \\
\hline 1 & 5 & 3 & 4 & 7 \\
\hline & 6 & 4 & 8 & 8 \\
\hline 2 & 2 & 3 & 1 & 7 \\
\hline & 9 & 4 & 9 & 8 \\
\hline
\end{tabular}

\subsection{Procedure}

The participants took part in three experimental sessions that were scheduled for $2 \mathrm{~h}$ each. The organization of the data collection is shown in Fig. 5 . In the first session, they signed the consent form to participate in the experiment, completed some timed tests and an untimed questionnaire (described below), and learned how to play the ER game. In the second and third sessions, the ER members and the attacker(s) played three games to generate data for the experimental analysis while wearing galvanic skin response (GSR) sensors, and then they provided ratings of workload and teammates' participation and leadership contributions. Because of the apparent difficulty of the simulation and absence of explicit time constraints in some experimental conditions, some groups facing two attackers were only able to complete two games in session 2. GSR data were not analyzed here, but see Guastello et al., 2016, Guastello et al., 2017a, Guastello et al., 2018 for three recent reports. An analysis of leadership ratings from the end of the sessions was reported separately (Guastello et al., 2016), and further reports are forthcoming.

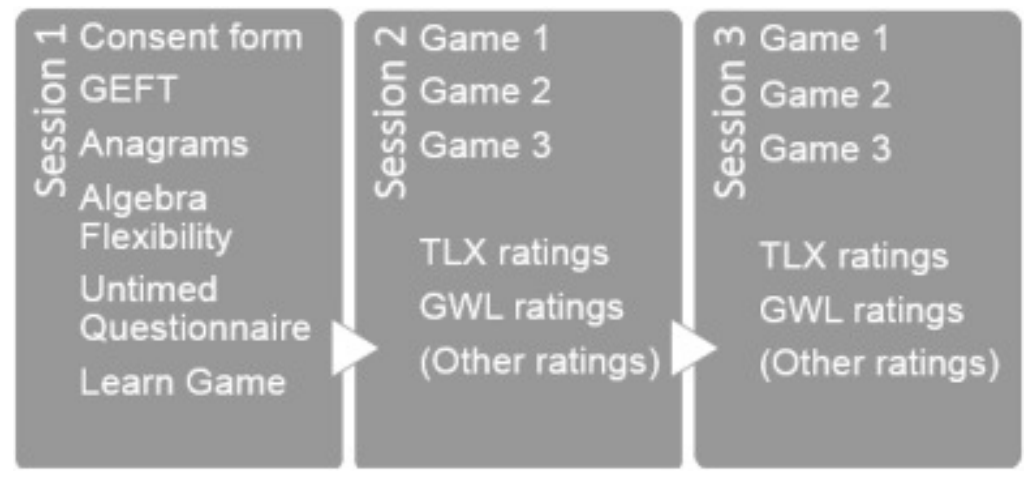

Fig. 5. Organization of data collection across three experimental sessions. 


\subsection{Experimental task}

The experimental medium was a board game entitled, The Creature that Ate Sheboygan (Guastello and Bond, 2004; Simulation Productions, 1979). For 28 of the groups, teams and attackers were given a time limit of $90 \mathrm{~s}$ per turn for all games across sessions (most turns required only 10-70 s to complete). The other 16 groups were given a time limit of $90 \mathrm{~s}$ during the third session only. Participants were given a $30 \mathrm{~s}$ warning if they took at least $60 \mathrm{~s}$ to make their moves.

The ER teams were given 5 min at the start of a game to position their tokens on the board in any manner they thought was strategic while the attacker waited in another room out of earshot. Attackers made the first move. A turn was defined as an attacker's move followed by a team response. For two-attacker conditions, the attackers shared the movement potential that was defined by the roll of the die. Attackers could burn buildings and eradicate ER teams' military, police, firefighting, and air power. The attacker, or pair of attackers, wins if they score at least 40 points against the ER team. The ER team wins if it cuts the attacker's defense power (or each attacker's defense power in a two-attacker condition) to zero. The game outcomes were close to equal in the one-attacker condition with the ER teams winning $53.7 \%$ of the games. ER teams won $16.5 \%$ of the games when playing against two attackers. The median game, across all experimental conditions, lasted 11 turns (95\%ile $=31$ turns) and $972.5 \mathrm{~s}(95 \%$ ile $=2920.0 \mathrm{~s})$ from the beginning of the attacker's first turn to the conclusion.

The laboratory layout is shown in Fig. 6. When the participants arrived for the second session, they selected their own positions at the table. After a roll of the die, the high-rolling individual was assigned the role of Attacker. The back-up person was determined by another roll of the die. Participants switched places as necessary. The ER team members were then given badges that identified them as ER1 through ER4 or ER8 according to their positions shown in the diagram. Once the attackers and back-ups were identified and the ER team members were numbered by distributing name tags, they maintained those designations through the series of six games unless a participant did not show up for the third experimental session. If a no-show occurred, the back-up person replaced the missing individual. ER team members, once they were numbered, were not required to remain in the seating positions shown in the diagram, but they usually did so.
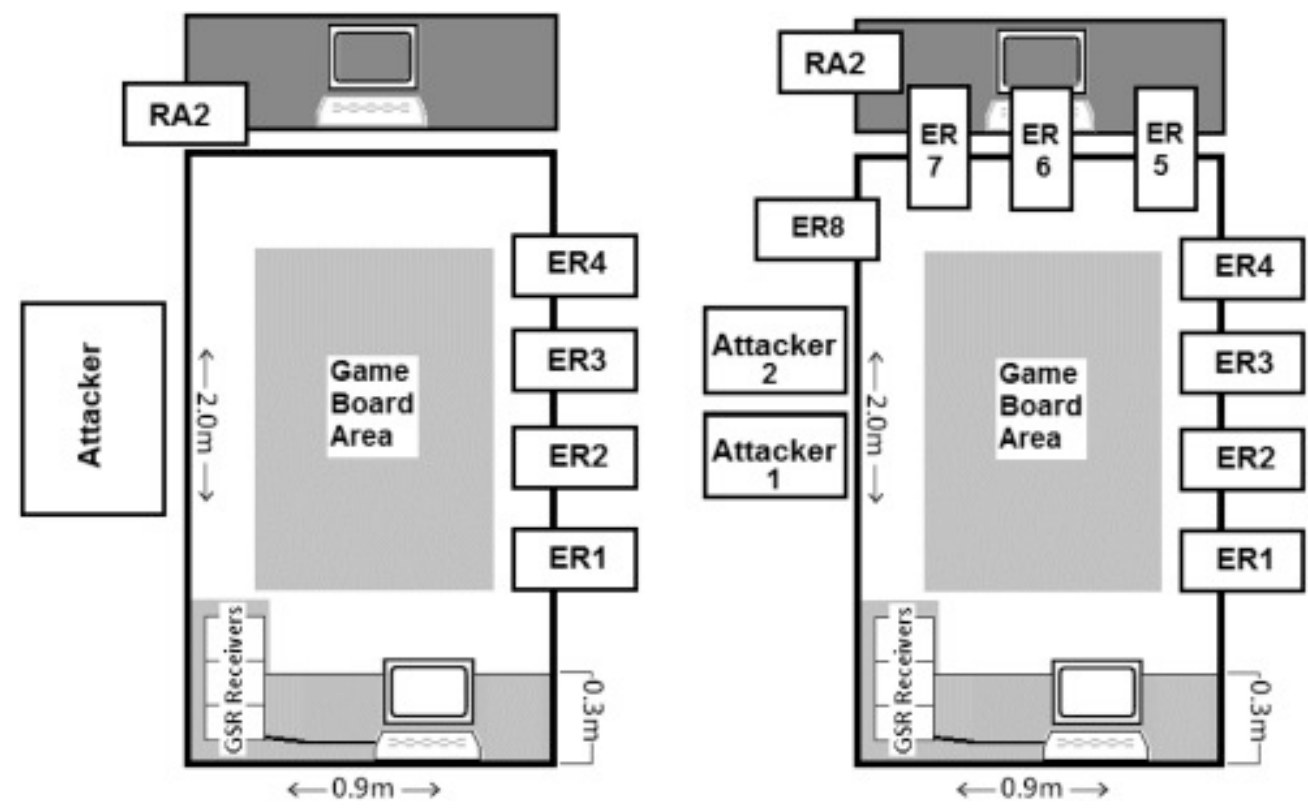

Fig. 6. Laboratory layout for the small (left) and large (right) groups. 
The research assistants (RA1 and RA2) were positioned at opposite ends of the table. RA1 was primarily responsible for managing the GSR data and was positioned at the laptop shown in the bottom of drawing. The table with the computer behind RA2 was not used in the experiment. Alternate participants who were not substituting for a player assisted the RAs by counting game points. The assisting participants were usually positioned close to RA1 but would move around to get a better view of the game board and players.

\subsection{Measurements}

The timed tests were field independence, anagrams, and algebra flexibility. The Group Embedded Figures Test (GEFT; Witkin et al., 2002) presents a simple geometric form and a complex geometric form. The participants were instructed to locate and trace the simple form that was embedded in the complex form. The GEFT consists of a 2-min timed section of practice items that are not scored and two 5-min timed groups of 12 items each that are scored. The split-half reliability values of the GEFT are 0.82 based on 177 adults and 0.85 based on 150 college students (Witkin et al., 2002).

The mixed anagram test was developed in our lab (Guastello, 2016a). There were 15 items; each consisted of a five-letter word that was scrambled with five random digits mixed in. The random digits placed additional demand on working memory. The participant was instructed to isolate the letters and rearrange them into a word. The vocabularywords for the anagrams were picked from words appearing on a spelling test used in previous experiments (Guastello et al., 2012a, $\underline{b}, \underline{c}$ ). The anagram test was delivered in paper-and-pencil format. After giving the instructions, the participants were given 5 min to complete the 15 items. The alpha reliability for this test was 0.79 based on a laboratory sample similar to the present one (Guastello, 2016a).

Algebra flexibility consisted of 8 items from the Flexibility Knowledge scale of the Contrasting Cases Harvard Algebra Project Assessment (Rittle-Johnson et al., 2009). The items focused on flexibility in problem solving. Alpha reliability for this scale based on a sample of middle school students was 0.81 (Rittle-Johnson and Star, 2009).

The untimed survey contained measures of coping flexibility, self-regulatory control, anxiety, emotional intelligence, conscientiousness, and empathy. Coping flexibility was measured by a 10-item questionnaire devised by Kato (2012). Item responses used a 1-5 scale such that $1=$ "never true of you," and $5=$ "nearly always true of you." An example item: "When a stressful situation has not improved, I try to think of other ways to cope with it." Kato (2012) reported alpha reliabilities ranging from 0.73 to 0.92 for different samples of adults. Alpha reliability based on a laboratory sample similar to the present one was 0.72 (Guastello et al., 2016).

Four coping variables for self-regulatory control were measured by the Strategic Flexibility Questionnaire devised by Cantwell and Moore (1996). This instrument has four scales: Monitoring ( 3 items), Planning (4 items), Inflexibility ( 7 items), and Irresolute ( 7 items). Item responses used the same 1-5 scale as for coping flexibility. Alpha reliabilities based on this sample were $0.66,0.51,0.85$, and 0.78 , respectively. Item sets for planning and monitoring were part of an Adaptive scale in the original exposition; Cantwell and Moore (1996) reported alpha reliabilities ranging from 0.79 to 0.87 for the three scales across different samples. Example item for Monitoring: "I believe that every problem has a particular way of being completed, and I adjust my methods of study when necessary" (p. 506). Example item for Planning: "Before starting work on a particular problem I like to play with a number of possible ways of attacking the problem" (p. 507). Example item for Inflexibility: "I rarely change the way I study, regardless of particular topic requirements" (p. 508). Example item for Irresolute: "I find that I'm easily distracted from my line of thought as I am working, and this often makes my work disjointed and uneven" (p. 509).

The anxiety test was a variation of the Taylor Manifest Anxiety Scale (Taylor, 1953) that was used in earlier research cognitive workload with the cusp model (Guastello et al., 2012a, $\underline{b}, \underline{c}$ ). The Taylor Manifest Anxiety Scale is centered on psychosomatic symptoms that do not comprise an alternative medical diagnosis when they 
appear in relatively large numbers. This measurement strategy was helpful previously in studies of occupational safety and health that also used cusp models (Guastello, 1995; Guastello and Lynn, 2014). It consisted of 19 statements such as, "I have nightmares about my job or classes." The participant responded by checking "Agree" ( 2 points), "?" (1 point), or "Disagree" (0 points). Some items were reverse scored $(\alpha=0.75)$.

The El scale was the 33-item scale developed by Schutte et al. (1998), which favors the aspect of the El construct that captures alexithymia more than it does cognitive judgment. Participants responded using a 5-point Likert scale; some items were reverse scored $(\alpha=0.82)$. An example item was: "When I am faced with obstacles, I remember times when I faced similar obstacles and overcame them."

The Empathy Assessment Index (Gerdes et al., 2011) was adopted as an empathy scale because it contained a reasonable balance between both the cognitive and emotional features of empathy, its psychometrics were good, and its administration time was brief. The scale consisted of 17 items with a 6-point response scale: 1 = never true, 2 = rarely true, 3 = sometimes true, 4 = frequently true, $5=$ usually true, 6 = always true. Two example items: "I can imagine what the character is feeling in a well-written book; "I can simultaneously consider my point of view and another person's point of view." The internal consistency of the Empathy Assessment Index was 0.81 based on 312 students (Gerdes et al., 2011). Its test-retest reliability ranged from 0.80 to 0.85 over a one-week period.

After the third game of each session, the participants removed their GSR sensors and immediately completed the TLX and GWL ratings of workload. Both inventories (defined in Table 1) were formatted as 20-point scales (1-21) anchored as 1 = "very low" and 21 = "very high." Ratings were completed by ER team members, attackers, and observers although only the ER teams' ratings were used.

There were two performance measures. One was the number of monsters killed by the ER team. The range in raw scores was 0 or 1 for a single game in the one-monster condition and 0-2 in the two-monster condition. Across the multiple games per session, the range was 0-3 in the one-monster condition, and 0-6 in the twomonster condition. The second measure was the number of game points accumulated by the ER team against the monsters. The range in raw scores was $0-14$ for a single game in the one-monster condition and 0-28 in the two-monster condition.

\subsection{Statistical analysis}

The first step was to determine how the 11 elasticity-rigidity variables could be organized into a smaller number of components. The solution to the best aggregation of elasticity-rigidity variables was determined with principal components analysis and direct oblimin rotation. The component loading criterion was 0.45 . The sample size was $\mathrm{N}=351$, including all ER team members, attackers, and alternate personnel who completed the same tests and surveys at the start of the first experimental session.

Step 2 in the aggregation process was to determine the proportion of team members who scored above the median on each of the 11 variables. For this purpose, frequency distributions were calculated based on a library of data collected from the present study plus five previous studies (Guastello, 2016a; Guastello et al., 2012c, 2013a, 2015a, 2016) The elasticity-rigidity data were collected before the experimental task in all previous experiments. The proportion variables were added together with equal weights in combinations that corresponded to the components in the principal components analysis.

The cusp analyses for fatigue were polynomial regression analogues of the cusp response surface:

$$
\Delta \mathrm{z}=\beta_{0}+\beta_{1} \mathrm{z}_{1}^{3}+\beta_{2} \mathrm{z}_{1}^{2}+\beta_{3} \mathrm{bz}_{1}+\beta_{4} \mathrm{a}
$$


where $z$ was the dependent measure observed at two points in time, $b$ was the bifurcation variable, $a$ was the asymmetry variable, $\Delta \mathrm{z}$ was the change in performance between the first and last simulation within an experimental session. All variables were transformed by location and scale (see Eq. (3)) before entering into the regression model (Guastello, 2011, 2013a), and are thus designated as $z$ instead of $y$. Location $(\lambda)$ is the lower limit of the variable, which is usually the lowest value obtained in the data collection. Scale $(s)$ is the ordinary standard deviation:

$$
z=(y-\lambda) / s
$$

The transformation by location and scale was applied separately for dependent measures that were observed over two points in time. The transformation serves three purposes: (a) it fixes a zero-point where the function is supposed to start, (b) it counteracts bias in parameter estimates that occurs when multiplicative variables have different variances, and (c) it transforms variables into ratio scales (if they are not already so), which is always implied by theoretical differential equations (Guastello and Gregson, 2011).

Multiple variables could be entered as $b$ or $a$, and they would have separate regression weights associated with them. The quadratic elementis optional; its significance indicates that catastrophic shifts in one direction outnumber shifts in the opposite direction. If statistical significance was not obtained for all the important terms in the model, the quadratic term would be dropped and the remainder of the model retested.

$R^{2}$ for the cusp model was compared with $R^{2}$ for two linear comparison models:

$$
\begin{gathered}
\Delta \mathrm{y}=\beta_{0}+\beta_{1} \mathrm{~b}+\beta_{2} \mathrm{a}, \\
y_{2}=\beta_{0}+\beta_{1} y_{1}+\beta_{2} b+\beta_{3} a .
\end{gathered}
$$

The linear models involve the same variables that are used as cusp control variables but without the nonlinear structures. Equation (4)describes a prediction of change in the dependent measure performance as a function of prior performance and the research variables. If $R^{2}$ for the cusp exceeds $R^{2}$ for Equation $(3)$, then the cusp would explain changes in performance better than the linear model. If $R^{2}$ for the cusp exceeded $R^{2}$ for the prepost linear model (Equation (5)), then it is possible to conclude that the cusp was the best explanation for change in performance over time. If on the other hand, $R^{2}$ for the pre-post model exceeded $R^{2}$ for the cusp, then one would conclude that behavioral outcomes stayed the same or changed only gradually; in that case the linear function was a better description of the data.

The multiple regression models were tested using backward elimination. Compared to forward or stepwise entry, backward elimination is most likely to capture a complementarity effect if it is present (Darlington, 1990). Complementarity occurs when the size of a weight associated with one variable becomes notably larger if another variable is entered; the effect is similar to that of a suppressor effect, except the changes in the signs of the weight or significance levels are not involved. The regression procedure adopted $p$ to enter a variable $=0.10$, and $p$ to remove a variable $=0.15$. A $p$-value of .10 is preferred because of the large differences in effect sizes that one might encounter for the cusp elements (Guastello, 2013a). 
The cusp models for workload would ordinarily be calculated with Equation (2) in which $\Delta \mathrm{z}$ represented a change across two conditions of workload for participants who experienced both conditions. In this experiment, however, the groups' performance in response to workload manipulations was assessed in two formats. One format examined workload effects that the participants experienced within only one workload condition. In this case, the static cusp model was used for analysis (Guastello, 2011, 2013a). The static model assesses the probability distribution of the dependent measure and its degree of association with a cusp function with the control parameters in their respective locations:

$$
p d f(z)=\xi \exp \left(\theta_{1} \mathrm{z}_{1}{ }^{4}+\theta_{2} z_{1}{ }^{3}+\theta_{3} z_{1}{ }^{2} \mathrm{~b}+\theta_{4} z_{1} \mathrm{a}\right)
$$

In Equation (6), $\operatorname{pdf}(z)$ is a probit transformation of $z, b$ is the bifurcation variable, and $a$ is the asymmetry variable. $\theta i$ are nonlinear regression weights. Once again, multiple variables could be entered as $b$ or $a$, and they would have separate regression weights associated with them. The cubic term would be dropped and the remainder of the model retested if the model was nonsignificant overall or if statistical significance for the leading power potential ( $z^{3}$ in Equation (2), and $z^{4}$ in Equation (6)) and at least one bifurcation variable were not obtained.

The linear comparisons for Equation (6) simplify to one model:

$$
y 2=\beta_{0}+\beta_{1} b+\beta_{2} a
$$

In the second format for the workload model, we examined changes in performance when the time constraint was introduced in session 3 rather than in session 2. The polynomial difference model (Equation (2)) was used for the analysis of time constraints across sessions. For both types of analysis, the verification of the cusp model in its entirety implies the verification of the presence of its two attractors, bifurcation structure, and saddle point.

\section{Results}

\subsection{Aggregation of elasticity-rigidity variables}

The principal components analysis with direct oblimin rotation produced four components. The emotional intelligence component (El; see Table 3 ) consisted of emotional intelligence, coping flexibility, decisiveness, and empathy. The uncertainty component consisted of indecisiveness, planning and monitoring. The anxious avoidance component consisted of anxiety, inflexibility, and a lack of planning. The fluid

intelligence component consisted of field independence, anagrams, and math flexibility. The correlations among the components ranged from -0.217 to 0.110 . The largest connection occurred between the El component and anxious avoidance $(p<.001)$. The correlations between fluid intelligence and other components were statistically significant $(p<.05)$, but they only accounted for $1 \%$ of each other's variance. Uncertainty was unrelated to the El component and the anxious avoidance component.

Table 3. Structure matrix for principal component analysis.

\begin{tabular}{|l|l|l|l|l|l|}
\hline \multicolumn{1}{|c|}{ Variable } & \multicolumn{2}{c|}{ Component Loading } & & \multicolumn{1}{c|}{ FI } \\
\hline Field Independence & .07 & Uncertainty & AA & \\
\hline Anagrams & .12 & -.16 & -.32 & $\underline{.60}$ \\
\hline Anxiety & -.37 & -.05 & .01 & $\underline{.76}$ \\
\hline
\end{tabular}




\begin{tabular}{|l|l|l|l|l|}
\hline Algebra Flexibility & -.06 & -.00 & .06 & .53 \\
\hline Emotional Intelligence & $\underline{.79}$ & .21 & -.03 & -.01 \\
\hline Coping Flexibility & $\underline{.62}$ & .38 & -.41 & .16 \\
\hline Irresolute & $\underline{-.49}$ & $\underline{.50}$ & .36 & -.33 \\
\hline Inflexibility & -.04 & .13 & $\underline{.82}$ & -.01 \\
\hline Planning & .17 & $\underline{.47}$ & $\underline{-.65}$ & -.02 \\
\hline Monitoring & .25 & $\underline{.81}$ & -.04 & .02 \\
\hline Empathy & .82 & -.01 & -.10 & -.01 \\
\hline Eigenvalue & 2.46 & 1.57 & 1.28 & 1.08 \\
\hline Pct Variance & 22.32 & 14.27 & 11.59 & 9.78 \\
\hline
\end{tabular}

Note: $\mathrm{EI}=$ emotional intelligence; $\mathrm{AA}=$ anxious avoidance; $\mathrm{FI}$ = fluid intelligence.

Loading criterion $=.45$

The second step in the aggregation process was to determine what proportion of team members scored above the median on each of the 11 variables. Frequency distributions were calculated based on a library of data collected from the present study plus five previous studies, as enumerated previously. Combined descriptive $\underline{\text { statistics appear in Table } 4 .}$

Table 4. Descriptive statistics for elasticity-rigidity variables combined from six studies.

\begin{tabular}{|l|l|l|l|l|l|l|}
\hline \multicolumn{1}{|c|}{ Variable } & \multicolumn{1}{c|}{$\mathbf{N}$} & \multicolumn{1}{c|}{ M } & \multicolumn{1}{c|}{ Mdn } & \multicolumn{1}{c|}{ SD } & \multicolumn{1}{c|}{ Min } & \multicolumn{1}{c|}{ Max } \\
\hline Anxiety & 1033 & 18.13 & 16.00 & 9.83 & 0.00 & 41.00 \\
\hline Emotional Intelligence & 1033 & 123.71 & 124.00 & 13.01 & 83.00 & 176.00 \\
\hline Coping Flexibility & 745 & 34.21 & 34.00 & 5.54 & 17.00 & 50.00 \\
\hline Empathy & 349 & 77.32 & 78.00 & 8.88 & 36.00 & 97.00 \\
\hline Monitoring & 744 & 13.28 & 13.00 & 2.41 & 6.00 & 20.00 \\
\hline Planning & 744 & 8.87 & 9.00 & 2.91 & 3.00 & 38.00 \\
\hline Inflexibility & 744 & 24.62 & 25.00 & 5.09 & 5.00 & 35.00 \\
\hline Irresolute & 744 & 19.95 & 20.00 & 4.87 & 1.00 & 33.00 \\
\hline Field Independence & 923 & 10.45 & 11.00 & 4.85 & 0.00 & 18.00 \\
\hline Algebra Flexibility & 471 & 8.77 & 9.00 & 1.62 & 1.00 & 15.00 \\
\hline
\end{tabular}

After counting the number of ER team members who scored above the median and dividing by the team size, the third step was to create group-level component variables by adding together the proportions for variables that met the criterion loading within each component. The descriptive statistics for the four group-level component variables appear in Table 5 and are based on $N=43$ groups; one group is not represented in the table because it contained too much missing data.

Table 5. Descriptive statistics for group-level elasticity-rigidity components and aggregated ratings of subjective workload.

\begin{tabular}{|l|l|l|l|l|l|}
\hline \multicolumn{1}{|c|}{ Variable } & N & \multicolumn{1}{c|}{ M } & \multicolumn{1}{c|}{ SD } & \multicolumn{1}{c|}{ Min } & \multicolumn{1}{c|}{ Max } \\
\hline El Component & 43 & 0.00 & 2.43 & -4.83 & 8.39 \\
\hline Uncertainty & 43 & 0.00 & 1.83 & -3.99 & 3.99 \\
\hline Anxious Avoidance & 43 & 0.00 & 1.61 & -3.28 & 4.11 \\
\hline Fluid Intelligence & 43 & 0.00 & 1.98 & -4.50 & 3.78 \\
\hline TLX Asymmetry & 82 & 18.93 & 5.31 & 7.00 & 30.33 \\
\hline TLX Bifurcation & 82 & 26.75 & 5.94 & 11.75 & 40.24 \\
\hline GWL Bifurcation & 75 & 65.82 & 10.35 & 31.99 & 90.00 \\
\hline
\end{tabular}




\subsection{Aggregation of TLX and GWL ratings}

TLX and GWL ratings were aggregated across team members and scales. The first step was to compute the mean ratings given by ER team members on each scale. The second step was to add the group means into broader variables that corresponded to either bifurcation or asymmetry variables in the cusp model. The standard deviations for the ratings were relatively equal, so they were simply added together, which is the common practice for composing total TLX ratings (Warm et al., 2008).

The TLX ratings were aggregated into two groups that were thought to correspond to the two control parameters in the cusp catastrophe model. The asymmetry group consisted of demands from the task: mental demand, physical demand, and temporal demand. The bifurcation group consisted of demands on the individual: performance, effort, and frustration. Descriptive statistics for the TLX composites and GWL variables appear in Table 5. The TLX data are based on 41 groups (after discounting those with missing data). The GWL data are based on somewhat more missing data because the original paper by Helton et al. (2014) was not published until this study was underway.

Table 6 shows the correlations between composite group measurements of elasticity-rigidity, ratings of workload, and team performance. A critical $p$-value of .10 was adopted for this analysis to compensate for low statistical power and to maintain consistency with other regressionanalyses. Both performance indices in session 2 were significantly correlated with the TLX bifurcation composite, but not with the other composites of workload ratings. There were no significant relationships $(p>.10)$ between the elasticity-rigidity composites with workload ratings or performance measures (latter not shown in the table).

Table 6. Correlations between composite group measurements of elasticity-rigidity, ratings of workload, and team performance $(\mathrm{N}=41)$.

\begin{tabular}{|l|l|l|l|}
\hline \multicolumn{1}{|c|}{ Variable } & TLX Asymmetry & TLX Bifurcation & GWL \\
\hline Session 2 & & & \\
\hline TLX Asymmetry & & $.56^{* * * *}$ & $.60^{* * * *}$ \\
\hline TLX Bifurcation & & & $.63^{* * * *}$ \\
\hline ER Team Game Points & -.03 & $.31^{* *}$ & .13 \\
\hline Monsters Killed & -.09 & $.37^{* *}$ & .06 \\
\hline El Component & -.09 & .01 & .06 \\
\hline Uncertainty & -.16 & -.21 & -.09 \\
\hline Anxious Avoidance & -.04 & -.03 & .22 \\
\hline Fluid Intelligence & -.21 & -.23 & -.11 \\
\hline Session 3 & & & \\
\hline TLX Asymmetry & & $.48^{* * *}$ & $.77^{* * * *}$ \\
\hline TLX Bifurcation & & & $.63^{* * * *}$ \\
\hline ER Team Game Points & -.03 & $.33^{* *}$ & .20 \\
\hline Monsters Killed & -.19 & $.38^{* *}$ & .11 \\
\hline El Component & $-.29^{*}$ & -.07 & -.11 \\
\hline Uncertainty & -.21 & -.04 & -.11 \\
\hline Anxious Avoidance & .16 & .08 & .10 \\
\hline Fluid Intelligence & $-.34 * *$ & -.14 & $.29 *$ \\
\hline P . 10 & & \\
\hline
\end{tabular}

$* p<.10$

$* * p<.05$,

$* * * p<.01$

$* * * * p<.001$.

The relationships between the workload ratings and performance remained the same in session 3 . A new relationship appeared, however, showing that teams with higher levels of fluid intelligence gave lower ratings of 
workload for mental, physical, and temporal demands. Two other weak trends took shape whereby teams with higher levels of fluid intelligence gave lower ratings of group workload $(p=.08)$, and teams with higher levels of emotional intelligence provided lower ratings for the TLX asymmetry composite $(p=.07)$.

\subsection{Cusp models for workload within sessions}

The analyses for workload used the static model (Equation (6)). Once again the observations from session 3 were combined with those of session 2, making the effective $\mathrm{N}=86$ group-session observations (see Fig. 7 , center panel). Session, scored dichotomously, was included as an asymmetry variable. For this analysis we adopted a strategy of variable entry by testing a model with the quartic term, TLX bifurcation, TLX asymmetry variables first. The TLX combination of mental, physical and temporal demand was used as the asymmetry variable. The TLX combination of performance, effort, and frustration was the bifurcation variable.

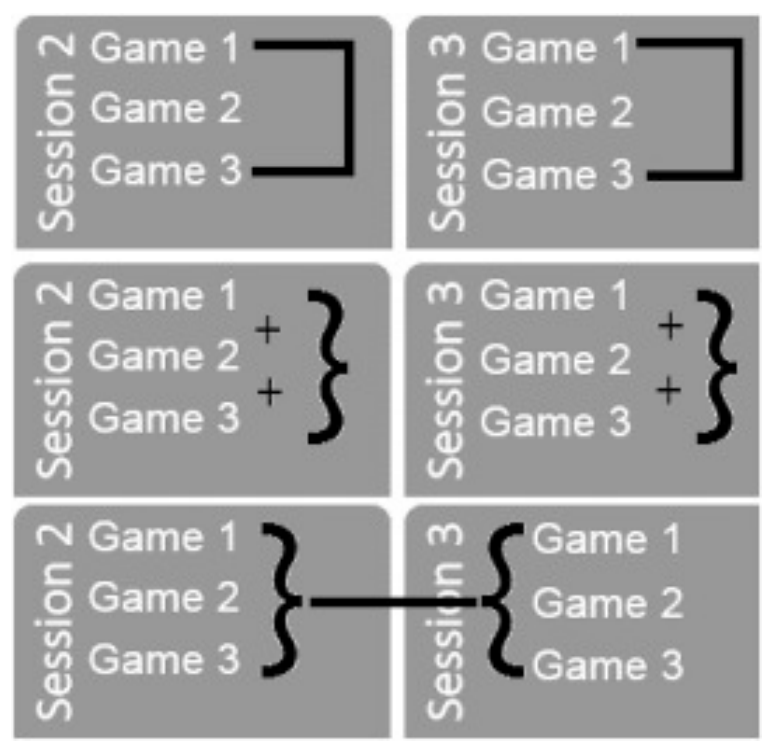

Fig. 7. Data comparisons for cusp analyses. Upper: fatigue examining differences in performance within sessions; data from the two sessions were analyzed together, and session was used as a variable.

Middle: workload examining performance across an entire sessions using the static model; data from the two sessions were analyzed together, and session was used as a variable. Lower: workload examining differences in performance across sessions with time pressure increasing or not.

In a second step, we entered the elasticity-rigidity bifurcation variables and GWL bifurcation variable. The dependent measure in the first analysis was the number of monsters killed. Results showed that the quartic, bifurcation, and asymmetry terms were significant as shown in Table 9. Session differences did not make a significant contribution to the workload model, and neither did the number of monsters or team size, even after removing the cubic term. The cusp in Table 7 was substantially more accurate than the linear comparison model, which also contained the two TLX variables but no other experimental conditions.

Table 7. Cusp catastrophe and linear comparison models for workload, within session, with monsters killed as the criterion.

\begin{tabular}{|l|l|l|}
\hline Element & $\theta$ & \\
\hline Cusp $R^{2}=.508$ & & \\
\hline$\xi$ & $45.160^{*}$ & \\
\hline$Z_{1}{ }^{4}$ & $0.075^{*}$ & \\
\hline$Z_{1}{ }^{3}$ & $0.262^{*}$ & \\
\hline$Z_{1}{ }^{*} T L X$ bifurcation & $0.033^{*}$ & \\
\hline
\end{tabular}




\begin{tabular}{|c|c|c|}
\hline $\mathrm{Z}_{1}^{*} \mathrm{TLX}$ asymmetry & $-0.098 *$ & \\
\hline $\mathrm{Z}_{1}^{*}$ Session & -0.007 & \\
\hline \multicolumn{3}{|c|}{ Linear model: $R^{2}=.296$, adj. $R^{2}=.277, F(2,72), 15.153, p<.001$} \\
\hline & $\beta$ & $t$ \\
\hline TLX bifurcation & 0.633 & $5.367^{* * * *}$ \\
\hline TLX asymmetry & -0.466 & $-3.954 * * * *$ \\
\hline \multicolumn{3}{|l|}{$* p<.10$} \\
\hline \multicolumn{3}{|l|}{$* * p<.05$} \\
\hline \multicolumn{3}{|l|}{$* * * p<.01$} \\
\hline
\end{tabular}

Further modeling attempts with the group-level elasticity-rigidity for GWL variables were not successful, and usually produced negative $R^{2}$ values for the cusp. The cusp model for the criterion of number of points accumulated by the ER teams and the TLX variables as control variables was not successful. In this case the best model was a linear model, which contained the two TLX composites and session differences. Performance points were higher within a session if the workload from performance, effort, and frustration were higher and if the mental, physical and temporal demands were lower (Table 8).

Table 8. Cusp catastrophe and linear comparison models for workload, within sessions, with ER teams' points totals as the criterion.

\begin{tabular}{|l|l|l|}
\hline Element & $\boldsymbol{\beta}$ & $\boldsymbol{t}$ \\
\hline Cusp $R^{2}=.000$ & & \\
\hline Linear model: $R^{2}=.214$, adj. $R^{2}=.191, F(2,73)=6.434, p<.001$ & & \\
\hline TLX bifurcation & 0.473 & $3.753^{* * * *}$ \\
\hline TLX asymmetry & -0.264 & $-2.095^{* *}$ \\
\hline Session & 0.206 & $1.950^{*}$ \\
\hline
\end{tabular}

$*_{p}<.10$

$* * p<.05$

$* * * p<.01$

$* * * * p<.001$

Table 9. Cusp catastrophe and linear comparison models for fatigue with monsters killed as the criterion.

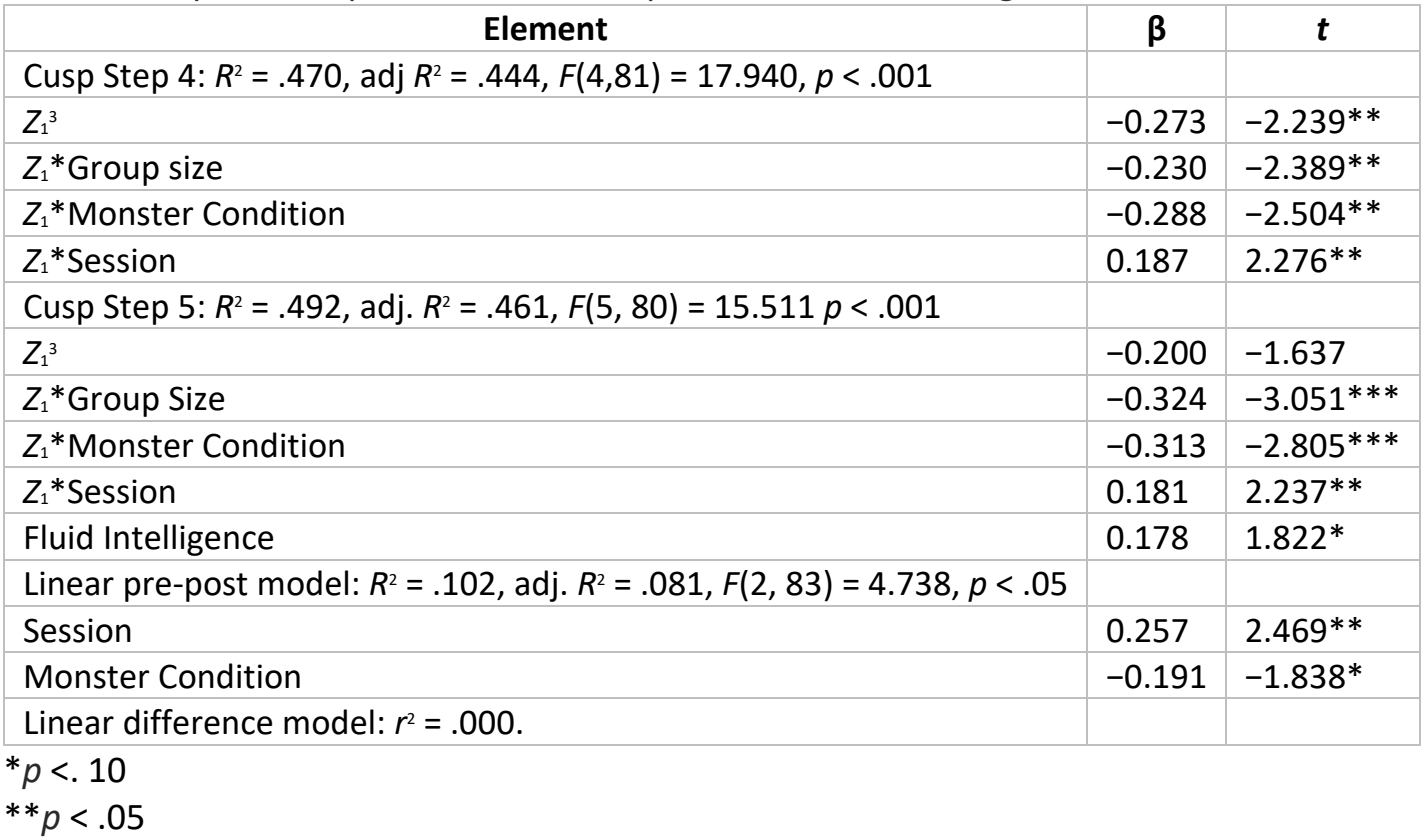


$* * * p<.01$

$* * * * p<.001$

Further analyses were conducted to determine if experimental conditions, GWL ratings, or elasticity-rigidity components added explanative value to the cusp or linear models. No further effects were found, and the modeling process was terminated with the results shown in Table 8.

\subsection{Cusp models for workload between sessions}

This analysis examined changes in performance between the two experimental sessions. For some groups the time constraint was introduced in session 3 and constituted a situation of increasing time pressure. For other groups the time constraint was introduced in session 2. The sample size was $\mathrm{N}=37$ groups after missing data were discounted. The four elasticity-rigidity composites, the GWL composite, and a TLX composite (performance, efforts, and frustration) were examined as bifurcation variables. Increasing time pressure, group size, number of attackers, and the other TLX composite (mental, physical, and temporal demand) were the asymmetry variables. Workload ratings were based on those given in session 3.

The results of the analysis indicated that discontinuous shifts in performance did not occur across sessions as a result of the time pressure manipulation because the leading power potential (cubic term), which is a distinguishing characteristic of the cusp model along with the bifurcation term, was not statistically significant. For the criterion of monsters killed, only one variable remained in the model, which the bifurcation term for the TLX composite $\left(r^{2}=0.356, p<.001\right)$. This variable was less accurate than using performance at time 1 (session 2$)$ as a predictor of performance change $\left(r^{2}=0.386, p<.001\right)$. The correlation between the unmoderated TLX bifurcation composite and performance change was not significant $\left(r^{2}=0.003\right)$.

For the criterion of points scored by the ER team, only one variable remained in the model here as well, which was the bifurcation term for the GWL composite $\left(r^{2}=0.513, p<.001\right)$. The direction of the correlation was negative meaning that larger positive changes in performance came from groups that performed less effectively than others initially and rated the group workload as lower. This variable was more accurate than the number of points scored in session 2 alone $\left(r^{2}=0.177, p<.01\right)$ and the unmoderated GWL composite as predictors of performance change. $\left(r^{2}=0.013, \mathrm{NS}\right)$.

\subsection{Cusp models for fatigue}

The cusp models for fatigue used polynomial difference Equation (2) for the analysis with Equations (4), (5)) along with the corresponding linear comparison measures. One performance criterion at time 1 was the number of monsters killed in the first of three games within a session, which was compared with the number of monsters killed in the third of three games (time 2). The second performance criterion was the number of points scored in game 1 (time 1) compared to the number of points scored in game 3 (time 2). There were 86 observations from the groups across two sessions. Session was tested as another bifurcation variable in the fatigue model, corresponding to work done. The strategy for data comparisons for the cusp models is shown in Fig. 6.

Results for the last two steps of the regression analysis for the cusp appear in Table 9 for the number of monsters killed. At step 4 it was clear that the critical elements for the cusp, the cubic and at least one bifurcation term, were obtained. Group size and number of monsters both corresponded to the amount of work done. Greater variability between the first and third games was associated with smaller groups and working against only one monster. Session also made a bifurcation effect with greater variability observed for session 3; this was an example of a learning effect, which could be related to both the team process and gaming strategy in the later session. 
The fluid intelligence component entered the equation at step 5 and thus acted as a compensatory ability. Fluid intelligence replaced the cubic term, indicating overlapping variance between fluid intelligence and the cubic term such that the latter no longer had a significant weight.

Both versions of the cusp model for number of monsters killed were clearly more accurate than the linear alternative models. The pre-post model (Equation (5)) showed that more performance improved in the third game of session 3 and if there was only one monster involved. No variables entered the linear difference model. The time 1 performance measure did not correlate with the time 2 performance measure in the pre-post model; this result indicated that performance was inconsistent over time.

Results for the regression analysis for the number of points obtained by the ER team appear in Table 10. The results for the cusp were simpler. Significant cubic and bifurcation terms were obtained. Group size and session functioned the same way as they did for the number of monsters killed. Fluid intelligence was again the asymmetry variable for compensatory ability.

Table 10. Cusp catastrophe and linear comparison models for fatigue with points obtained by the ER teams as the criterion.

\begin{tabular}{|l|l|l|}
\hline \multicolumn{1}{|c|}{ Element } & \multicolumn{1}{c|}{$\boldsymbol{~} \boldsymbol{c}$} & \multicolumn{1}{c|}{$\boldsymbol{t}$} \\
\hline Cusp: $R^{2}=.594$, adj. $R^{2}=.573, F(4,80)=29.216, p<.001$ & & \\
\hline$Z_{1}{ }^{*}$. & -0.538 & $-5.828^{* * * *}$ \\
\hline$Z_{1}{ }^{*}$ Group Size & -0.350 & $-3.186^{* * *}$ \\
\hline$Z_{1}^{*}$ Session & 0.163 & $2.285^{* *}$ \\
\hline Fluid Intelligence & 0.180 & $1.917^{*}$ \\
\hline Linear pre-post model: & $r^{2}=.073$ & \\
\hline Session & 0.269 & $2.548^{* *}$ \\
\hline Linear difference model: $r^{2}=.039$ & & \\
\hline Monster condition & -0.198 & $-1.855^{*}$ \\
\hline
\end{tabular}

$* p<.10$

$* * p<.05 * * * p<.01$

$* * * * p<.001$

The difference in $R^{2}$ between the cusp and next best alternative model was larger for the criterion of points obtained. The pre-post model only showed that there was more of a performance increase for the second session. The linear difference model contained one variable, which was monster condition. This showed that change in relative number of points accumulated was less, or more negative, if two monsters were involved.

\subsection{Summary of results}

The results are summarized in Table 11 and organized relative to the original hypotheses. Fig. 8 illustrates the placement of research variables on the cusp diagrams based on the empirical results. The overall interpretation is presented next.

Table 11. Summary of hypotheses and results.

\begin{tabular}{|c|c|c|c|}
\hline Hypothesis & & $\begin{array}{l}\text { Supported or } \\
\text { Not }\end{array}$ & \\
\hline \multirow[t]{2}{*}{1} & $\begin{array}{l}\text { Principal Component structure resembling original constructs or } \\
\text { emergent constructs }\end{array}$ & $\begin{array}{l}\text { YES. Two of } \\
\text { each }\end{array}$ & \\
\hline & & Monsters Killed & $\begin{array}{l}\text { Game } \\
\text { Points }\end{array}$ \\
\hline 2 & Cusp for workload more accurate than linear model within sessions & YES & NO \\
\hline $2 \mathrm{~A}$ & Experimental conditions as asymmetry variables & NO & \\
\hline
\end{tabular}




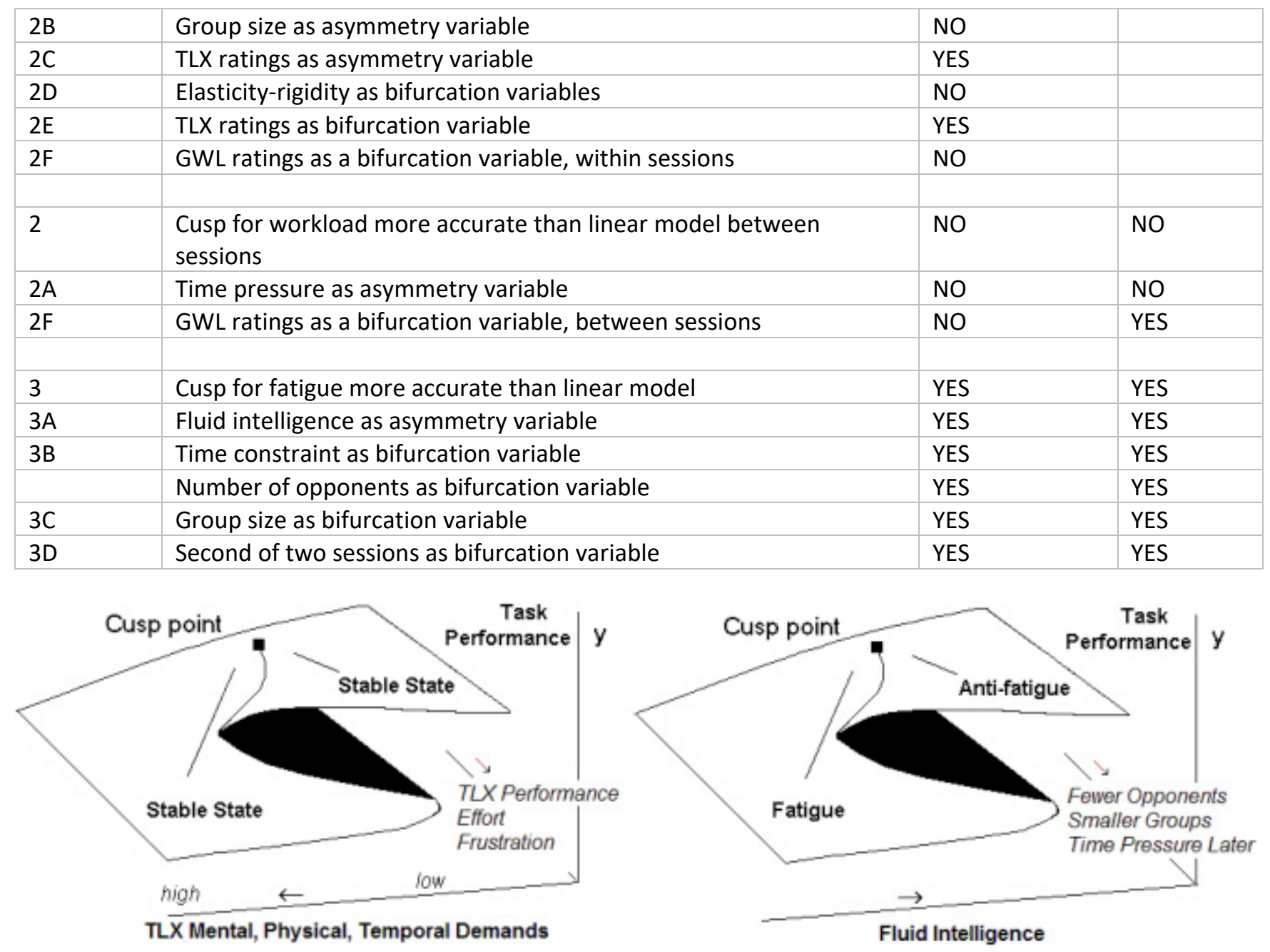

Fig. 8. Summary of results for cognitive workload and fatigue in the ER simulation.

\section{Discussion}

The central objective of this study was to extend the twin cusp models for cognitive workload and fatigue to group-level dynamics. Previous research showed that the two nonlinear models have been useful for analyzing individual and group workload and fatigue, both of which strongly impacted task performance (Guastello et al., 2017a; Guastello and Marra, 2018). Statistical modeling for nonlinear processes that permit point estimation is essential for the effective description and prediction of group working processes. The present study investigated the cusp dynamics in conjunction with specific individual and teamwide variables including affective, cognitive, and interpersonal components and participants' perceptions of workload (as control variables) for their further impact on two team performance variables. Initially, individual differences were aggregated for elasticity-rigidity variables, compensatory abilities, and workload ratings into group-level indications. The results of the present study opened the possibility that aggregated individual differences become subordinate to aggregated ratings of subjective workload across team members.

\subsection{Elasticity-rigidity components}

The principle components analysis of elasticity-rigidity produced four constructs; however, the patterns of covariance in the components analysis differed somewhat from conceptual classifications (hypothesis 1). Emotional intelligence combined with empathy and coping flexibility to produce an El component. Anxiety combined with two cognitive coping variables to produce a component denoting anxious avoidance. Three of 
the cognitive coping variables combined to produce a "response to uncertainty" component depicting response to uncertainty. Finally, the three cognitive variables formed the fluid intelligencedomain.

The primary difference between the original classifications and the component structure was the connection between anxiety and other variables. The new empathy scale by Gerdes et al. (2011) and Lietz et al. (2011) is conceptually similar to El, so it was not surprising that empathy and El formed their own component. Anxiety, in contrast, was more closely aligned with maladaptive coping strategies; the anxious avoidance and EI components were negatively correlated. The theme underlying the anxious avoidance component reflects the association between negative affect and rigidity reported by Liu and Wang (2014). The uncertainty and fluid intelligence components were consistent with the original taxonomy of constructs.

Another concurrent study from the same data base showed numerous links between both TLX and GWL ratings with elasticity-rigidity that were over and above the influences of the experimental manipulations (Guastello et al., 2017b). Anxiety was the most frequently occurring link from among the elasticity-rigidity variables. Elasticityrigidity variables only accounted for about $3 \%$ of the variance in workload ratings beyond what was accounted for by experimental conditions using linear regression analysis. Canonical correlation analysis between the set of elasticity-rigidity variables and experimental conditions on the one hand, and the 12 workload ratings on the other, showed stronger but more complex relationships. Some of the canonical variates involved combinations of TLX and GWL ratings, and others involved GWL ratings only.

\subsection{Cusp for workload}

The analyses for the cusp model for workload (hypothesis 2) indicated that all the workload dynamics occurred within experimental session, and there were little additional dynamics across experimental sessions. The analysis for workload using the static cusp model and criterion of monsters killed contained all the necessary parts of the model: the quartic term, TLX asymmetry (hypothesis $2 \mathrm{~B}$ ), and TLX bifurcation (hypothesis $\left.2 \mathrm{E} ; R^{2}=0.508\right)$. It was more accurate than the linear alternative $\left(R^{2}=0.296\right)$, which verified that the nonlinear relationships that were theoretically involved added to the explanation and prediction of workload beyond simple linear relationships among variables. Experimental conditions (hypotheses 2A and 2B), elasticity-rigidity (2D), and GWL ratings (2F) did not show any additional impact.

Previously we have shown that TLX and GWL ratings are responsive to workload manipulations for group size, number of attackers, differences between experimental sessions, and time constraints at the individual level (Guastello and Marra, 2018). The time constraint manipulation required an interaction term with the differences between sessions. Team size affected four out of six TLX ratings, but none of the GWL ratings. The number of attackers, however, affected both TLX and GWL ratings. The session-by-time constraint interaction affected TLX ratings for performance and frustration but none of the GWL ratings.

Discontinuities in performance were not detected, however, for the criterion of game points scored by the ER teams. Performance was associated with a linear combination of the two TLX composites and differences between sessions $\left(R^{2}=0.214\right)$. The regression weights for the two TLX composites pointed in opposite directions, however, suggesting that the groups that performed better were those that detected greater demands for performance and effort relative to their ratings of mental, physical and temporal demands of the experimental conditions. The effect of experimental session was modest but did indicate an improvement during session 3, which could have resulted from both task learning and interpersonal entrainment.

The cusp for workload that assessed performance changes across sessions, hypothetically in response to changes in time constraints, did not work out as planned. It was interesting, nonetheless, that the observed changes in performance were a result of an interaction between earlier performance and the perceptions of group workload later on. A previous study (Guastello and Marra, 2018) reported that demands from communication, coordination, team support and team dissatisfaction dropped in session 3. A strong initial 
start in session 2 combined with improvements in group process led to better performance in terms of points scored, but not necessarily in the actual defeating of monsters. This relationship was essentially a stand-alone bifurcation effect. The hypothesis that led to it was not evident from previous workload research and only became possible with the cusp theory.

\subsection{Cusp for fatigue}

The cusp models for fatigue worked out clearly for both criteria (hypothesis 3 ). The cusp model was more accurate $\left(R^{2}=0.492\right)$ than the best linear alternative $\left(R^{2}=0.102\right)$. The bifurcation parameter, which represented amount of work accomplished, contained three variables for the criterion of monsters killed: number of attackers (hypothesis 3B), group size (3C), and experimental session (3D). Performance was more variable between the first and third games within a session among smaller groups and groups with only one attacker. Performance across games was also discrepant in the later session. Notably, all groups were operating under the same time constraints in session 3 . The level of fluid intelligence within the group reflected a set of compensatory abilities $(3 \mathrm{~A})$. Comparable results were obtained for the fatigue modelusing the criterion of game points obtained by the ER teams $\left(R^{2}=0.573\right)$. This model was also more accurate than the better linear alternative $\left(R^{2}=0.073\right)$.

\subsection{Limitations and future research}

Previous studies with the cusp models for workload and fatigue using individual-level performance showed some notable variability among experimental tasks in that some tasks produced stronger workload effects than fatigue effects, and other tasks produced greater fatigue than workload effects (Guastello, 2014a). In this case, a strong workload effect was obtained for one of two performance criteria, and a strong fatigue effect was obtained for both criteria. One could speculate that actually killing monsters was a more decisive outcome than collecting points, which they would do to some extent regardless of the game's outcome. As the old saying goes, "close" only counts in horseshoes and hand grenades. The difference in performance criteria was apparently not a problem with the fatigue models. One distinctive feature, and possibly a glaring limitation, of the present study was that the ER simulation was a competitive task. The opponents, who were selected at random, could have been strong or weak players, which would alter the outcomes for the ER team. Future research could devote some attention to (a) revisiting the group processes and experimental conditions studied here with a strictly cooperative task and (b) how the characteristics of measurements interact with competition versus cooperation. This distinction might enable more precise mapping of discontinuous changes that occur over time.

Another issue that requires further investigation is the role of individual differences in elasticity-rigidity in collective group performance. It could be possible that transforming individual data into composite form may have obscured the individual and interactive effect(s) of specific variables. For instance, anxiety plays a role as a bifurcation factor in team performance by contributing both positive and negative influences (Ein-Dor et al., 2010; Guastello and Lynn, 2014; Naber et al., 2015). Anxiety is not always expressed as avoidance. As such, anxious avoidance might not be the expression of anxiety that is best controlled via El. It could also be the case that groups containing one or two people scoring higher on the El component could negate the impact of group members scoring high on anxious avoidance. In other words, the effect of anxiety on performance might be stronger in individual tasks where the high-El people are not present.

Thus, one strategy for future research would be to deliberately manipulate group composition, which was not done in this study. Naber et al. (2015) manipulated anxiety in small groups and found that the presence of one anxious individual produced the bifurcation effect. It is possible that a single person with a unique characteristic can make more of a difference in the group outcomes than varying group averages on some of these variables. The recruitment and selection of enough teams based on the number of elasticity-rigidity variables used here would be neigh impractical considering the number of experimental conditions involved and the time it would take to recruit a sufficient pool to select from, schedule the participants and sessions, and complete the 
experiment in the time available. Our present approach to group composition is closer to a common real-world situation in which group composition is uncontrolled. A group that is available for a task could assemble from a myriad of different backgrounds with task-relevant knowledge, skills, experience, and common purpose. The emergent or self-organizing process by which a group dynamic is formed from interacting individuals should foster productive bilateral and multilateral interactions, but nothing about the self-organizing or emergence process prevents the outcomes from going awry.

Group size was hypothesized to contribute to the workload level in the cusp model, but it did not do so. Group size did contribute to the fatigue model, however, as an element of work completed in the course of an experimental sessions. According to one perspective on group size (Guastello, 2010), if a simple relationship between group size and performance does not favor either larger or smaller groups, then it is likely that the task was dominated by the most competent individual or widespread social loafing. It is possible that the ER task did not engage participants' interest. This possibility could also explain the lack of connection between group size and GWL ratings in Guastello and Marra (2018). Future research should investigate this possibility by designing tasks that require specific individual responsibilities within the groups' performance efforts.

The result concerning GWL and prior performance predicting performance changes indicated that a group dynamic was taking form, but it was not fully completed. If the process had run its full course, a significant cubic term would also appeared in the cusp model, and when combined with the bifurcation effect, would have indicated that two stable states were present. Yet, the strong effect for the GWL bifurcation variable did indicate that the internal group processes were self-organizing toward better performance in terms of game points, which might have transcended to more victories over monsters. Future research should plan group studies over longer time horizons so that the groups would have more time to mature.

Improvements across the two sessions were previously noted for communication, coordination, time sharing and team dissatisfaction (Guastello and Marra, 2018). Further research should examine the relationship between GWL ratings, behavioral expressions of communication and coordination, and common patterns of autonomic arousal. The latter have a partial connection to behavioral coordination when the behaviors of team members are not meant to be precisely rhythmic but require coordinating timing nonetheless (Guastello et al., 2017a, $\underline{b}, \underline{2018})$. Communication patterns are now thought to represent both group cognition and a type of coordination with regard to information flow among team members (Cooke, 2015; Gorman, 2014; Shockley et al., 2009). In principle, demands should be less if the communication and coordination processes improve. It also appears, however, that people who are more socially sensitive could rate the demands higher than would less sensitive individuals. Thus there is a need to take individual differences such as empathy and emotional intelligence into consideration when interpreting social types of workload ratings.

\section{Conclusion}

The study used two different statistical methods for assessing the cusp catastrophe models for cognitive workload and fatigue. Both procedures permitted literal tests of the nonlinear processes with all its specific contributing elements. The average $R^{2}$ for the six cusp models $(0.410$, including those where only a bifurcation effect was found) was nearly twice as large as the next best linear explanation (0.208). The ratio was much greater in favor of the cusp model for fatigue (6.17:1) compared to the ratio for workload (1.28:1), suggesting that the ER simulation was producing stronger fatigue effects than workload effects.

The groups that were more prone to discontinuous performance change with regard to either workload or fatigue were those that scored high or low on the bifurcation variables as specified in Table 7, Table 9, Table 10. Those that buckled under workload reported greater workload from performance demands, effort demands, and frustration. Additionally they would move closer to the threshold for positive performance change if mental, physical, and temporal demands were rated lower. Groups that showed the greatest discontinuity arising from fatigue were smaller in size, competed against only one opponent, and had the time condition introduced in the 
later session. Positive change (antifatigue) was more likely for groups with higher average levels of fluid intelligence. This composite of cognitive variables suggests that groups with the right intellectual resources could compensate for fatigue in their performance.

The relative importance of specific elasticity-rigidity and subjective ratings of workload could turn out to be task dependent for group tasks as they have been for individual tasks. In the case of team workload dynamics, subjective ratings that were combined across team members had a stronger impact on performance than individual differences in elasticity-rigidity. Moreover, the average ratings of individual workload were more closely connected to performance dynamics than the ratings of group workload. As individual workload dynamics are scaled up to group level dynamics, the basic structural models still hold true (i.e., the cusp function), but the contributing variables are more focused on the task and less on the individual differences. The fatigue dynamics did not appear to be affected by these differences in scale.

\section{Acknowledgments}

This research was funded by a Way-Klingler Fellowship grant from Marquette University. The authors wish to thank Kaitlyn Bishop, Nicholas Callard, Julian Castro, Maribeth Gomez, Michael Equi, Michael Esson, Jacqueline Hackmon, Harli Hancock, Liana Harriri, and Claire Perna for their assistance with data collection and data management. A report based on this research was presented at the 27th annual conference of the Society for Chaos Theory in Psychology \& Life Sciences, Cincinnati, Ohio in August 2017.

\section{References}

Ackerman, 2011 P.L. Ackerman (Ed.), Cognitive Fatigue, American Psychological Association, Washington, DC (2011)

Alessandri et al., 2018 G. Alessandri, E. Perinelli, E. De Longis, A. Theodorou Second-order growth mixture modeling in organizational psychology: an application in the study of job performance using the cusp catastrophe model Nonlinear Dynam. Psychol. Life Sci., 22 (2018), pp. 53-76

Ash, 2014 J.E. Ash Fatigue and its effects upon control Arch. Psychol., 31 (2014), pp. 1-61

Baddeley, 2003 A. Baddeley Working memory: looking back and looking forward Nat. Rev. Neurosci., 4 (2003), pp. 829-839, 10.1038/nrnl201

Barron, 1955 F. Barron The disposition toward originality J. Abnorm. Soc. Psychol., 51 (1955), pp. 478-

485, 10.1037/h0048073

Barrouillet et al., 2011 P. Barrouillet, S. Portrat, V. Camos On the law relating processing to storage in working memory Psychol. Rev., 118 (2011), pp. 175-192, 10.1037/a0022324

Boehm-Davis et al., 2015 D.A. Boehm-Davis, F.T. Durso, J.D. Lee (Eds.), APA Handbook of Human Systems

Integration, American Psychological Association, Washington, DC (2015)

Bonito and Hollingshead, 1997 J.A. Bonito, A.B. Hollingshead Participation in small groups

B.R. Burleson (Ed.), Communications Yearbook, 20, Sage, Thousand Oaks, CA (1997), pp. 227-

261, 10.1080/23808985.1997.11678943

Butner et al., 2014 J.E. Butner, H.L. Dyer, T.S. Malloy, L.V. Kranz Uncertainty in cost performance as a function of the cusp catastrophe in the NASA program performance management system Nonlinear Dynam. Psychol.

Life Sci., 18 (2014), pp. 397-418

Cantwell and Moore, 1996 R.H. Cantwell, P.J. Moore The development of measures of individual differences in self-regulatory control and their relationship to academic performance Contemp. Educ. Psychol., 21 (1996), pp. 500-517, 10.1006/ceps.1996.0034

Cattell, 1994 H.E.P. Cattell Development of the 16PF fifth edition S.R. Conn, M.L. Rieke (Eds.), Technical

Manual (16PF fifth ed.), Institute for Personality and Ability Testing, Champaign, IL (1994), pp. 1-20

Cohen, 1980 S. Cohen Aftereffects of stress on human performance and social behavior: a review of research and theory Psychol. Bull., 88 (1980), pp. 82-108

Comer, 1995 D.R. Comer A model of social loafing in real work groups Hum. Relat., 48 (1995), pp. 647-667

Conrad, 1951 R. Conrad Speed and load stress in a sensorimotor skill Br. J. Ind. Med., 8 (1951), pp. 1-7 
Cooke, 2015 N.J. Cooke Team cognition as interaction Curr. Dir. Psychol. Sci., 24 (2015), pp. $415-$

419, 10.1177/0963721415062474

Costa and McCrae, 1992 P.T. Costa, R.R. McCrae Four ways five factors are basic Pers. Indiv. Differ., 13 (1992), pp. 653-665, 10.1016/0191-8869(92)90236-I

Cox-Fuenzalida et al., 2006 L.-E. Cox-Fuenzalida, A. Angie, S. Holloway, L. Sohl Extraversion and task

performance: a fresh look through the workload history lens J. Res. Pers., 40 (2006), pp. 432-

439, 10.1016/i.jrp.2005.02.003

Darlington, 1990 R.B. Darlington Regression and Linear Models McGraw-Hill, New York (1990)

Dennis and Valacich, 1993 A.R. Dennis, J.S. Valacich Computer brainstorms: more heads are better than one J. Appl. Psychol., 78 (1993), pp. 531-537, 10.1037/0021-9010.78.4.531

Dodge, 1917 R. Dodge The laws of relative fatigue Psychol. Rev., 24 (1917), pp. 89-113, 10.1037/h0075549

Ein-Dor et al., 2010 T. Ein-Dor, M. Mikulincer, G. Doron, P.R. Shaver The attachment paradox: how can so many of us (the insecure ones) have no adaptive advantages Perspect. Psychol. Sci., 5 (2010), pp. 123-

$141,10.1177 / 1745691610362349$

Escartin et al., 2013 J. Escartin, L. Ceja, J. Navarro, D. Zapf Modeling workplace bullying using catastrophe theory Nonlinear Dynam. Psychol. Life Sci., 17 (2013), pp. 493-516

Fan and Smith, $2017 \mathrm{~J}$. Fan, A.P. Smith The impact of workload and fatigue on performance

L. Longo, M.C. Leva (Eds.), Mental Workload: Models and Applications, Springer, Cham, Switzerland (2017), pp. 90-105, 10.1007/978-3-319-61061-0 6

Funke et al., 2012 G.J. Funke, B.A. Knott, E. Salas, D. Pavlas, A.J. Strang Conceptualization and measurement of team workload: a critical need Hum. Factors, 54 (2012), pp. 36-51, 10.1177/0018720811427901

Gerdes et al., 2011

K.E. Gerdes, C.A. Leitz, E.A. Segal Measuring empathy in the 21st century: development of an empathy index rooted in social cognitive neuroscience and social justice Soc. Work. Res., 35 (2011), pp. 83 -

3, 10.1093/swr/35.2.83

Gilmore, 1981 R. Gilmore Catastrophe Theory for Scientists and Engineers Wiley, New York (1981)

Goldstein, 2011 J. Goldstein Emergence in complex systems P. Allen, S. Maguire, B. McKelvey (Eds.), The Sage

Handbook of Complexity and Management, Sage, Thousand Oaks, CA (2011), pp. 65-78

Gorman, 2014 J.C. Gorman Team coordination and dynamics: two central issues Curr. Dir. Psychol.

Sci., 37 (2014), pp. 255-285, 10.1177/0963731414545215

Gorman et al., 2017 J.C. Gorman, T.A. Dunbar, D. Grimm, C.L. Gipson Understanding and modeling teams as

dynamical systems Front. Psychol., 8 (2017), p. 1053, 10.3389/psyc.2017.01053

Gruszka et al., 2010 A. Gruszka, G. Matthews, B. Szymura (Eds.), Handbook of Individual Differences in

Cognition: Attention Memory and Executive Control, Springer, New York (2010)

Guastello, 1985 S.J. Guastello Euler buckling in a wheelbarrow obstacle course: a catastrophe with complex lag Behav. Sci., 30 (1985), pp. 204-212, 10.1002/bs.3830300405

Guastello, 1995 S.J. Guastello Chaos, Catastrophe, and Human Affairs: Applications of Nonlinear Dynamics to

Work, Organizations, and Social Evolution Lawrence Erlbaum, Mahwah, NJ (1995)

Guastello, 2002 S.J. Guastello Managing Emergent Phenomena: Nonlinear Dynamics in Work Organizations

Lawrence Erlbaum Associates, Mahwah, NJ (2002)

Guastello, 2003 S.J. Guastello Nonlinear dynamics, complex systems, and occupational accidents Hum. Factors.

Manuf., 13 (2003), pp. 293-304

Guastello, 2005 S.J. Guastello Statistical distributions and self-organizing phenomena: what conclusions should be drawn? Nonlinear Dynam. Psychol. Life Sci., 9 (2005), pp. 463-478

Guastello, 2009 S.J. Guastello Group dynamics: adaptability, coordination, and the emergence of leaders

S.J. Guastello, M. Koopmans, D. Pincus (Eds.), Chaos and Complexity in Psychology: Theory of Nonlinear

Dynamical Systems, Cambridge University Press, New York (2009), pp. 402-433

Guastello, 2010 S.J. Guastello Nonlinear dynamics of team performance and adaptability in emergency

response Hum. Factors, 52 (2010), pp. 162-172, 10.1177/0018720809359003 
Guastello, 2011 S.J. Guastello Catastrophe models with nonlinear regression

S.J. Guastello, R.A.M. Gregson (Eds.), Nonlinear Dynamical Systems Analysis for the Behavioral Sciences Using Real Data, C R C Press/Taylor \& Francis, Boca Raton, FL (2011), pp. 305-318

Guastello, 2013a S.J. Guastello Catastrophe theory and its applications to I/O psychology

J.M. Cortina, R. Landis (Eds.), Frontiers of Methodology in Organizational Research, Routledge/Society for

Industrial and Organizational Psychology, New York, NY (2013), pp. 29-61

Guastello, 2013b S.J. Guastello Emergence in organizations and human collective intelligence

J.D. Lee, A. Kirlik (Eds.), Oxford Handbook of Cognitive Engineering, Oxford University Press, New York (2013), pp. 534-555

Guastello, 2014a S.J. Guastello Catastrophe models for cognitive workload and fatigue: memory functions, multitasking, vigilance, financial decisions and risk Proc. Hum. Factors Ergon. Soc., 58 (2014), pp. 908-

912, 10.1177/1541931214581190

Guastello, 2014b S.J. Guastello Human Factors Engineering and Ergonomics: a Systems Approach (second

ed.), CRC Press, Boca Raton, FL (2014)

Guastello, 2016a S.J. Guastello Cognitive Workload and Fatigue in Financial Decision Making

Springer, Tokyo (2016)

Guastello, 2016b S.J. Guastello Physiological synchronization in a vigilance dual task Nonlinear Dynam. Psychol.

Life Sci., 20 (2016), pp. 49-80

Guastello, 2017 S.J. Guastello Nonlinear dynamical systems for theory and research in ergonomics

Ergonomics, 60 (2017), pp. 167-193, 10.1080/00140139.2016.1162851

Guastello and Bond, 2004 S.J. Guastello, R.W. Bond Jr. Coordination learning in Stag Hunt games with

application to emergency management Nonlinear Dynam. Psychol. Life Sci., 8 (2004), pp. 345-374

Guastello and Gregson, 2011 S.J. Guastello, R.A.M. Gregson (Eds.), Nonlinear Dynamical Systems Analysis for the Behavioral Sciences Using Real Data, C R C Press/Taylor \& Francis, Boca Raton, FL (2011)

Guastello and Liebovitch, 2009 S.J. Guastello, L.S. Liebovitch Introduction to nonlinear dynamics and

complexity S.J. Guastello, M. Koopmans, D. Pincus (Eds.), Chaos and Complexity in Psychology: Theory of

Nonlinear Dynamical Systems, Cambridge University Press, New York, NY (2009), pp. 1-

$0,10.1017 /$ CBO9781139058544.002

Guastello and Lynn, 2014 S.J. Guastello, M. Lynn Catastrophe model of the accident process, safety climate, and anxiety Nonlinear Dynam. Psychol. Life Sci., 18 (2014), pp. 177-198

Guastello and Marra, 2018 S.J. Guastello, D.E. Marra External validity and factor structure of individual and group workload ratings: the potential influence of self-organizing processes Theor. Issues Ergon.

Sci., 19 (2018), pp. 229-253, 10.1080/1463922X.2017.1356395

Guastello and McGee, 1987 S.J. Guastello, D.W. McGee Mathematical modeling of fatigue in physically

demanding jobs J. Math. Psychol., 31 (1987), pp. 248-269

Guastello et al., 2012a

S.J. Guastello, H. Boeh, M. Schimmels, H. Gorin, S.Huschen, E. Davis, N.E. Peters, M. Fabisch, K. Poston Cusp catastrophe models for cognitive workload and fatigue in a verbally-cued pictorial memory task Hum.

Factors, 54 (2012), pp. 811-825, 10.1177/0018720812442537

Guastello et al., 2012b S.J. Guastello, H. Boeh, C. Shumaker, M. Schimmels Catastrophe models for cognitive workload and fatigue Theor. Issues Ergon. Sci., 13 (2012), pp. 586-602, 10.1080/1463922X.2011.552131

Guastello et al., 2012c S.J. Guastello, H. Gorin, S. Huschen, N.E. Peters, M.Fabisch, K. Poston New paradigm for task switching strategies while performing multiple tasks: entropy and symbolic dynamics analysis of voluntary patterns Nonlinear Dynam. Psychol. Life Sci., 16 (2012), pp. 471-497

Guastello et al., 2013a S.J. Guastello, H. Boeh, H. Gorin, S. Huschen, N.E. Peters, M. Fabisch, K. Poston Cusp catastrophe models for cognitive workload and fatigue: a comparison of seven task types Nonlinear Dynam. Psychol. Life Sci., 17 (2013), pp. 23-47

Guastello et al., 2013b

S.J. Guastello, H. Gorin, S. Huschen, N.E. Peters, M.Fabisch, M. Fabisch, K. Poston, K. Weinberger The minimum entropy principle and task performance Nonlinear Dynam. Psychol. Life Sci., 17 (2013), pp. 405-423 
Guastello et al., 2014 S.J. Guastello, M. Malon, P. Timm, K. Weinberger, H. Gorin, M. Fabisch, K. Poston Cusp catastrophe models for cognitive workload and fatigue in a vigilance dual task Hum. Factors, 56 (2014), pp. 737-751, 10.1177/0018720813508777

Guastello et al., 2015a Guastello, K. Reiter, M. Malon, P. Timm, A. Shircel, J.Shaline Catastrophe models for cognitive workload in N-back tasks Nonlinear Dynam. Psychol. Life Sci., 19 (2015), pp. 173-200

Guastello et al., 2015b S.J. Guastello, A. Shircel, M. Malon, P. Timm Individual differences in the experience of cognitive workload Theor. Issues Ergon. Sci., 16 (2015), pp. 20-52, 10.1080/1463922X.2013.869371

Guastello et al., 2016 S.J. Guastello, K. Reiter, M. Malon Cognitive workload and fatigue in a vigilance dual task: miss errors, false alarms, and the impact of wearing biometric sensors while working Nonlinear Dynam.

Psychol. Life Sci., 20 (2016), pp. 509-535

Guastello et al., 2017a S.J. Guastello, A.N. Correro II, D.E. Marra, M. Michels, H.Schimmel Elasticity and rigidity constructs and ratings of subjective workload for individuals and groups L. Longo, M.C. Leva (Eds.), Mental

Workload: Models and Applications, Springer, Cham, Switzerland (2017), pp. 51-76, 10.1007/978-3-319-61061$\underline{04}$

Guastello et al., 2017b S.J. Guastello, D.E. Marra, J. Castro, M. Equi, A.F. Peressini Turn taking, team synchronization, and non-stationarity in physiological time series Nonlinear Dynam. Psychol. Life Sci., 21 (2017), pp. 319-332

Guastello et al., 2018 S.J. Guastello, D.E. Marra, A.F. Peressini, J. Castro, M.Gomez Autonomic synchronization, team coordination, participation and performance Nonlinear Dynam. Psychol. Life Sci., 22 (2018), pp. 359-394 Hakstian and Cattell, 1978 A.R. Hakstian, R.B. Cattell Higher-stratum ability structures on a basis of twenty primary abilities J. Educ. Psychol., 70 (1978), pp. 657-669, 10.1037/0022-0663.70.5.657

Hancock, 2007 P.A. Hancock On the process of automation transition in multitask human-machine systems IEEE Trans. Syst. Man Cybern. Syst. Hum., 37 (2007), pp. 586-598

Hancock and Desmond, 2001 P.A. Hancock, P.A. Desmond (Eds.), Stress, Workload, and Fatigue, Lawrence Erlbaum Associates, Mahwah, NJ (2001)

Hancock and Warm, 1989 P.A. Hancock, J.S. Warm A dynamic model of stress and sustained attention Hum.

Factors, 31 (1989), pp. 519-537, 10.7771/2327-2937.1024

Hancock et al., 1995 P.A. Hancock, G. Williams, C.M. Manning Influence of task demand characteristics on

workload and performance Int. J. Aviat. Psychol., 5 (1995), pp. 63-86

Hart, 2008 S.G. Hart NASA-task load index (NASA-TLX) 20 Years later Proc. Hum. Factors Ergon. Soc., 50 (2008), pp. 904-908, 10.1177/154193120605000909

Hart and Staveland, 1988 S.G. Hart, L.E. Staveland Development of the NASA task load index (TLX): results of experimental and theoretical research P.A. Hancock, N. Meshkati (Eds.), Human Workload, North

Holland, Amsterdam (1988), pp. 138-183, 10.1016/S0166-4115(08)62386-9

Hazy and Boyatsis, 2015 J.K. Hazy, R.E. Boyatsis Emotional contagion and proto-organizing in human interaction dynamics Front. Psychol., 6 (2015), p. 806, 10.3389/psyg.2015,00806

Helton and Russell, 2011 W.S. Helton, P.N. Russell Working memory load and the vigilance decrement

Exp. Brain Res., 212 (2011), pp. 429-437 10.1007_s00221-011-2749-1

Helton and Russell, 2013 W.S. Helton, P.N. Russell Visuospatial and verbal working memory load: effects on visuospatial vigilance Exp. Brain Res., 224 (2013), pp. 429-436 10.1007_s00221-012-3322-2

Helton and Russell, 2015 W.S. Helton, P.N. Russell Rest is best: the role of rest and task interruptions on vigilance Cognition, 134 (2015), pp. 165-173, 10.1016/j.cognition.2014.10.001

Helton et al., 2014 W.S. Helton, G.J. Funke, B.A. Knott Measuring workload in collaborative contexts: trait versus state perspectives Hum. Factors, 56 (2014), pp. 322-332, 10.1177/0018720813490727

Hockey, 1997 G.R.J. Hockey Compensatory control in the regulation of human performance under stress and high workload: a cognitive-energetical framework Biol. Psychol., 45 (1997), pp. 73-93

Hockey, 2011 G.R.J. Hockey A motivational control theory of cognitive fatigue P. Ackerman (Ed.), Cognitive Fatigue, American Psychological Association, Washington, DC (2011), pp. 167-187 
Hockey, 2012 B. Hockey Challenges in fatigue and performance research

G. Matthews, P.A. Desmond, C. Neubauer, P.A. Hancock (Eds.), The Handbook of Operator

Fatigue, Ashgate, Aldershot, Hampshire, UK (2012), pp. 45-60

Hollnagel, 2012 E. Hollnagel FRAM: The Function Resonance Analysis Method: Modelling Complex Socio-

technical Systems Ashgate, Burlington, VT (2012)

Hollnagel et al., 2006 E. Hollnagel, D.D. Woods, N. Leveson (Eds.), Resilience Engineering, Ashgate, Burlington, VT (2006)

Hong, 2010 S.L. Hong The entropy conservation principle: applications in ergonomics and human factors Nonlinear Dynam. Psychol. Life Sci., 14 (2010), pp. 291-315

Jacobsen and Guastello, 2007 J.J. Jacobsen, S.J. Guastello Nonlinear models for the adoption and diffusion of innovations for industrial energy conservation Nonlinear Dynam. Psychol. Life Sci., 11 (2007), pp. 499-520 Jacobsen and Guastello, 2011 J.J. Jacobsen, S.J. Guastello Diffusion models for innovation: S-curves, networks, power laws, catastrophes, and entropy Nonlinear Dynam. Psychol. Life Sci., 15 (2011), pp. 307-333

Jansen et al., 2016 R.J. Jansen, B.D. Sawyer, R. van Egmond, H. de Ridder, P.A. Hancock Hysteresis in mental workload and task performance: the influence of demand transitions and task prioritization Hum.

Factors, 58 (2016), pp. 1143-1157, 10.1177/0018720816669271

Kane and Engle, 2002 M.J. Kane, R.W. Engle The role of prefrontal cortex in working-memory capacity, executive attention, and general fluid intelligence: an individual-differences perspective Psychonomic Bull. Rev., 9 (2002), pp. 617-671, 10.3758/BF03196323

Kane et al., 2005 M.J. Kane, D.Z. Hambrick, A.R.A. Conway Working memory capacity and fluid intelligence are strongly related constructs: comment on Ackerman, Beier, and Boyle (2005) Psychol. Bull., 131 (2005), pp. 6671, 10.1037/0033-2909.131.1.66

Kantowitz, 1985 B.H. Kantowitz Channels and stages in human information processing: a limited analysis of theory and methodology J. Math. Psychol., 29 (1985), pp. 135-174, 10.1016/0022-2496(85)90014-8

Kantowitz and Sorkin, 1983 B. Kantowitz, D. Sorkin Human Factors: Understanding People-system Relationships Wiley, New York (1983), 10.1037/a0027770

Karwowski, 2012 W. Karwowski A review of human factors challenges of complex adaptive systems:

discovering and understanding chaos in human performance Hum. Factors, 54 (2012), pp. 983-

995, 10.1177/0018720812467459

Katerelos and Varotsis, 2017 I. Katerelos, N. Varotsis A cusp catastrophe model of tax behavior Nonlinear

Dynam. Psychol. Life Sci., 21 (2017), pp. 89-112

Katerndahl, 2011 D. Katerndahl Is research publication a catastrophic phenomenon? Nonlinear Dynam. Psychol. Life Sci., 11 (2011), pp. 253-264

Katidioti and Taatgen, 2014 I. Katidioti, N.A. Taatgen Choice in multitasking: how delays in the primary task turn a rational into an irrational multitasker Hum. Factors, 56 (2014), pp. 728-736, 10.1177/0018720813504216 Kato, $2012 \mathrm{~T}$. Kato Development of the coping flexibility scale: evidence for the coping flexibility hypothesis $\mathrm{J}$. Counsel. Psychol., 59 (2012), pp. 262-273, 10.1037/0022-3514.37.6.822

Kiefer and Myer, 2015 A.W. Kiefer, G.D. Myer Training the antifragile athlete: a preliminary analysis of neuromuscular training effects on muscle activation dynamics Nonlinear Dynam. Psychol. Life Sci., 19 (2015), pp. 489-510

Kroll, 1981 W. Kroll The C. H. McCoy research lecture: analysis of local muscle fatigue patterns Res. Q. Exerc. Sport, 52 (1981), pp. 523-539

Latané et al., 1979 B. Latané, K. Williams, S. Harkins Many hands make light the work: the cases and consequences of social loafing J. Pers. Soc. Psychol., 37 (1979), pp. 822-832, 10.1037/0022-3514.37.6.822 Lietz et al., 2011 C.A. Lietz, K.E. Gerdes, F. Sun, J.M. Geiger, M.A. Wagaman, E.A.Segal The Empathy Assessment Index (EAI): a confirmatory factor analysis of a multidimensional model of empathy J. Soc. Soc. Work. Res., 2 (2011), pp. 104-124, 10.5243/jsswr.2011.6

Liu and Wang, 2014 Y. Liu, Z. Wang Positive affect and cognitive control: approach-motivation intensity influences the balance between cognitive flexibility and stability Psychol. Sci., 25 (2014), pp. 1116$1123, \underline{10.1177 / 0956797614525213}$ 
Logie, 2011 R.H. Logie The functional organization and capacity limits of working memory Curr. Dir. Psychol. Sci., 20 (2011), pp. 240-245, 10.1177/0963721411415340

MacLean and Arnell, 2012 M.H. MacLean, K.M. Arnell Personality predicts temporal attention costs in the attentional blink paradigm Psychonomic Bull. Rev., 17 (2012), pp. 556-562, 10.3758/PBR.17.4.556

Matthews et al., 2012 G. Matthews, P.A. Desmond, C. Neubauer, P.A. Hancock(Eds.), The Handbook of Operator Fatigue, Ashgate, Aldershot, Hampshire, UK (2012)

Morgan and Hancock, 2011 J.F. Morgan, P.A. Hancock The effect of prior task loading on mental workload: an example of hysteresis in driving Hum. Factors, 43 (2011), pp. 75-86, 10.1177/0018720810393505

Mosso, $1894 \mathrm{~A}$. Mosso La fatigue intellectuelle et physique [Mental and physical fatigue] Alcon, Paris, France (1894)

Naber et al., 2015 A.M. Naber, J.N. McDonald, O.A. Asenuga, W. Arthur Jr. Team members' interaction anxiety and team training effectiveness: a catastrophic relationship? Hum. Factors, 57 (2015), pp. 163-

$176,10.1177 / 0018720814538814$

Newhouse et al., 1978 R. Newhouse, D. Ruelle, F. Takens Occurrence of strange attractors: an axiom near quasi-periodic flows on Tm, $\mathbf{m}>\mathbf{3}$ Commun. Math. Phys., 64 (1978), pp. 35-41

Oberauer and Kleigel, $2006 \mathrm{~K}$. Oberauer, R. Kleigel A formal model of capacity limits in working memory J. Mem. Lang., 55 (2006), pp. 601-626, 10.1016/iml.2006.08.009

Oliva and McDade, 2008 T.A. Oliva, S.R. McDade A catastrophe model for the prospect-utility theory question Nonlinear Dynam. Psychol. Life Sci., 12 (2008), pp. 261-280

Pascual-Leone, $1970 \mathrm{~J}$. Pascual-Leone A mathematical model for the transition rule in Piaget's developmental stages Acta Psychol., 32 (1970), pp. 301-345, 10.1016/0001-6918(70)90108-3

Pincus and Metten, 2010 D. Pincus, A. Metten Nonlinear dynamics in biopsychosocial resilience Nonlinear Dynam. Psychol. Life Sci., 14 (2010), pp. 353-380

Ralph et al., 2010 J. Ralph, W.D. Gray, M.J. Schoelles Squeezing the balloon: analyzing the unpredictable effects of cognitive workload Proc. Hum. Factors Ergon. Soc., 54 (2010), pp. 299-303, 10.1177/154193121005400407 Rebelo et al., 2016 T. Rebelo, D. Stamovlasis, P.R. Lourenço, I. Dimas, M. Pinheiro A cusp catastrophe model for team learning, team potency and team culture Nonlinear Dynam. Psychol. Life Sci., 20 (2016), pp. 537-564 Reuter-Lorenz and Cappell, 2008 P.A. Reuter-Lorenz, K.A. Cappell Neurocognitive aging and compensation hypothesis Curr. Dir. Psychol. Sci., 17 (2008), pp. 177-182, 10.1111/j.1467-8721.2008.00570.x

Rittle-Johnson and Star, 2009 B. Rittle-Johnson, J.R. Star Compared with what? The effects of different comparisons on conceptual knowledge and procedural flexibility for equation solving J. Educ.

Psychol., 101 (2009), pp. 529-544, 10.1037/a0014224

Rittle-Johnson et al., 2009 B. Rittle-Johnson, J.R. Star, K. Durkin The importance of prior knowledge when comparing examples: influences on conceptual and procedural knowledge of equation solving J. Educ. Psychol., 101 (2009), pp. 836-852, 10.1037/a0016026

Rose et al., 2002 C.L. Rose, L.B. Murphy, L. Byard, K. Nikzad The role of the big five personality factors in vigilance performance and workload Eur. J. Pers., 16 (2002), pp. 185-200, 10.1002/per.451

Rubinstein et al., 2001 J.S. Rubinstein, D.E. Meyer, J.E. Evans Executive control of cognitive processes in task

switching J. Exp. Psychol. Hum. Percept. Perform., 27 (2001), pp. 763-797, 10.1037/0096-1523.27.4.763

Sawyer, 2005 R. Sawyer Social Emergence: Societies as Complex Systems Cambridge University Press, New York, NY (2005), 10.1017/CBO9780511734892

Schneider et al., 2011 M. Schneider, B. Rittle-Johnson, J.R. Star Relations among conceptual knowledge, procedural knowledge, and procedural flexibility in two sample differing in prior knowledge Dev.

Psychol., 47 (2011), pp. 1525-1538, 10.1037/a0024997

Schuldberg, 2015 D. Schuldberg What is optimum variability? Nonlinear Dynam. Psychol. Life Sci., 19 (2015), pp. 553-568

Schutte et al., 1998 N.S. Schutte, J.M. Malouf, L.E. Hall, D.J. Haggerty, J.T. Cooper, C.J. Golden, L. Dornheirn Development and validation of a measure of emotional intelligence Pers. Indiv. Differ., 25 (1998), pp. 167$177, \underline{10.1016 / S 0191-8869(98) 00001-4}$ 
Sellers et al., 2014 J. Sellers, W.S. Helton, K. Näswall, G.J. Funke, B.A. Knott Development of the team workload questionnaire (TWLQ) Proc. Hum. Factors Ergon. Soc., 58 (2014), pp. 989-993, 10.1177/1541931214581207 Sheridan, 2008 T.B. Sheridan Risk, human error, and system resilience: fundamental ideas Hum. Factors, 50 (2008), pp. 418-426, 10.1518/001872008X250773 Shockley et al., 2009 K. Shockley, D.C. Richardson, R. Dale Conversation and coordinative structures Top. Cognitive Sci., 1 (2009), pp. 305-319, 10.1111/i.1756-8765.2009.01021.x Simulation ProductionsInc., 1979 Simulation Productions, Inc The Creature that Ate Sheboygan! Wreak Havoc with the Monster of Your Choice Author, New York, NY (1979) Sprott, 2003 J.C. Sprott Chaos and Time Series Analysis Oxford, New York (2003) Stamovlasis, 2006 D. Stamovlasis The nonlinear dynamical hypothesis in science education problem solving: a catastrophe theory approach Nonlinear Dynam. Psychol. Life Sci., 10 (2006), pp. 37-70 Stamovlasis, 2011 D. Stamovlasis Nonlinear dynamics and neo-Piagetian theories in problem solving: perspectives on a new epistemology and theory development Nonlinear Dynam. Psychol. Life Sci., 15 (2011), pp. 145-173

Stamovlasis and Sideridis, 2014 D. Stamovlasis, G.D. Sideridis Ought-approach versus ought-avoidance: nonlinear effects on arousal under achievement situations Nonlinear Dynam. Psychol. Life Sci., 18 (2014), pp. 67-90, 10.1002/sce.21002

Stamovlasis and Tsaparlis, 2012 D. Stamovlasis, G. Tsaparlis Applying catastrophe theory to an informationprocessing model of problem solving in science education Sci. Educ., 96 (2012), pp. 392-410 Stamovlasis and Vaiopoulou, 2017 D. Stamovlasis, J. Vaiopoulou The role of dysfunctional myths in a decisionmaking process under bounded rationality: a complex dynamical systems perspective Nonlinear Dynam. Psychol. Life Sci., 21 (2017), pp. 267-288

Starch and Ash, 1917 D. Starch, I.E. Ash The mental curve of work Psychol. Rev., 24 (1917), pp. 391-402 Sulis, 2009 W. Sulis Collective intelligence: observations and models

S.J. Guastello, M. Koopmans, D. Pincus (Eds.), Chaos and Complexity in Psychology: Theory of Nonlinear Dynamical Systems, Cambridge University Press, New York, NY (2009), pp. 41-72

Szalma, 2012 J.L. Szalma Individual differences in stress, fatigue, and performance

G. Matthews, P.A. Desmond, C. Neubauer, P.A. Hancock (Eds.), The Handbook of Operator Fatigue, Ashgate, Aldershot, Hampshire, UK (2012), pp. 75-90

Szalma and Teo, 2012 J.L. Szalma, G.W.L. Teo Spatial and temporal task characteristics as stress: $a$ test of the dynamic adaptability theory of stress, workload, and performance Acta Psychol., 139 (2012), pp. 471485, 10.1016/j.actpsy.2011.12.009 Taleb, 2012 N. Taleb Antifragile: Things that Gain from Disorder Random House, New York (2012) Taylor, 1953 J.A. Taylor A personality scale of manifest anxiety J. Abnorm. Soc. Psychol., 48 (1953), pp. 285290, 10.1037/h0056264 Thom, 1975 R. Thom Structural Stability and Morphegenesis Addison-Wesley, New York (1975) Thompson, 2010 H.L. Thompson The Stress Effect: Why Smart Leaders Make Dumb Decisions - and what to Do about it Jossey-Bass, San Francisco (2010) Thomson et al., 2015 D.R. Thomson, D. Besner, D. Smilek A resource-control account of sustained attention: evidence from mind-wandering and vigilance paradigms Perspect. Psychol. Sci., 10 (2015), pp. 8296, 10.1177/1745691614556681 Vyal et al., 2012 K. Vyal, B. Cornwell, N. Arkin, C. Grillon Describing the interplay between anxiety and cognition: from impaired performance under low cognitive load to reduced anxiety under high load Psychophysiology, 49 (2012), pp. 842-852, 10.1111/j.1469-8986.2012.01358.x Warm et al., 2008 J.S. Warm, R. Parasuraman, G. Matthews Vigilance requires hard mental work and is stressful Hum. Factors, 50 (2008), pp. 433-441, 10.1518/001872008X312151

Whelan, 2009 S. Whelan Group size, group development, and group productivity Small Group Res., 40 (2009), pp. 247-262, 10.1177/1046496408328703

Wickens, 2002 C.D. Wickens Multiple resources and performance prediction Theor. Issues Ergon. Sci., 3 (2002), pp. 159-177, 10.1080/14639220210123806 
Wickens, 2008 C.D. Wickens Multiple resources and mental workload Hum. Factors, 50 (2008), pp. 449455, 10.1518/001872008X288394

Witkin et al., 2002 H.A. Witkin, P.K. Oltman, E. Raskin, S.A. Karp A Manual for the Embedded Figures Test (second ed.), Consulting Psychologists Press, Palo Alto, CA (2002)

Zander, 1994 A. Zander Making Groups Effective (second ed.), Jossey-Bass, San Francisco (1994)

Zeeman, 1977 E.C. Zeeman Catastrophe Theory: Selected Papers 1972-1977 Addison-Wesley, Reading, MA (1977) 